OAK RIDGE
NATIONAL LABORATORY

MANAGED BY UT-BATTELLE FOR THE DEPARTMENT OF ENERGY

\title{
Low Velocity Sphere Impact of a Borosilicate Glass
}

T. G. Morrissey, M. K. Ferber, A. A. Wereszczak, * and E. E. Fox, Ceramic Science and Technology Group Materials Science and Technology Division Oak Ridge National Laboratory

Oak Ridge, TN 37831-6068

* Corresponding Author wereszczakaa@ornl.gov

Publication Date: May 2012

Prepared by the OAK RIDGE NATIONAL LABORATORY

Oak Ridge, Tennessee 37831 managed by

UT-BATTELLE, LLC for the U.S. DEPARTMENT OF ENERGY Under contract DE-AC05-00OR22725

US ARMY TARDEC

DISTRIBUTION STATEMENT A.

Approved for public release; distribution unlimited. 


\section{DOCUMENT AVAILABILITY}

Reports produced after January 1, 1996, are generally available free via the U.S. Department of Energy (DOE) Information Bridge:

Web site: $h$ ttp://www.osti.gov/bridge

Reports produced before January 1, 1996, may be purchased by members of the public from the following source:

National Technical Information Service

5285 Port Royal Road

Springfield, VA 22161

Telephone: 703-605-6000 (1-800-553-6847)

TDD: $703-487-4639$

Fax: 703-605-6900

E-mail: info@ntis.fedworld.gov

Web site: http://www.ntis.gov/support/ordernowabout.htm

Reports are available to DOE employees, DOE contractors, Energy Technology Data Exchange (ETDE) representatives, and International Nuclear Information System (INIS) representatives from the following source:

Office of Scientific and Technical Information

P.O. Box 62

Oak Ridge, TN 37831

Telephone: $865-576-8401$

Fax: 865-576-5728

E-mail: reports@osti.gov

Web site: http://www.osti.gov/contact.html

This report was prepared as an account of work sponsored by an agency of the United States Government. Neither the United States government nor any agency thereof, nor any of their employees, makes any warranty, express or implied, or assumes any legal liability or responsibility for the accuracy, completeness, or usefulness of any information, apparatus, product, or process disclosed, or represents that its use would not infringe privately owned rights. Reference herein to any specific commercial product, process, or service by trade name, trademark, manufacturer, or otherwise, does not necessarily constitute or imply its endorsement, recommendation, or favoring by the United States Government or any agency thereof. The views and opinions of authors expressed herein do not necessarily state or reflect those of the United States Government or any agency thereof. 


\section{TABLE OF CONTENTS}

Page

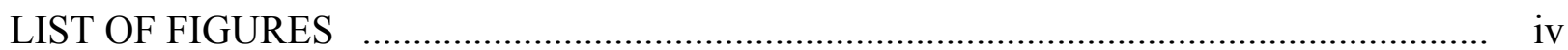

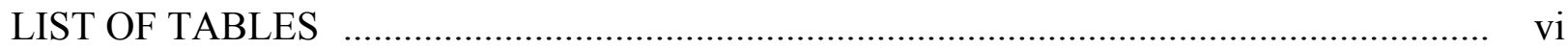

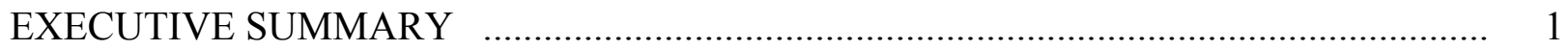

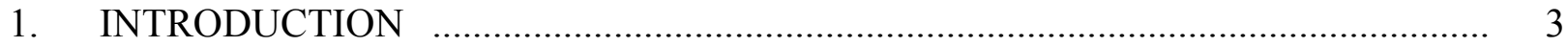

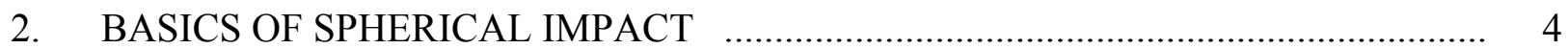

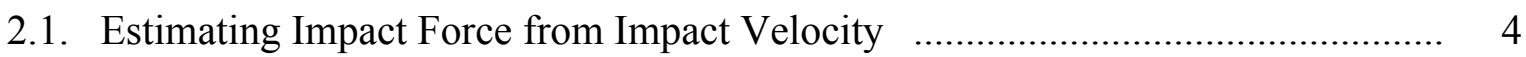

2.2. Comparing Different Sphere Materials .................................................... 6

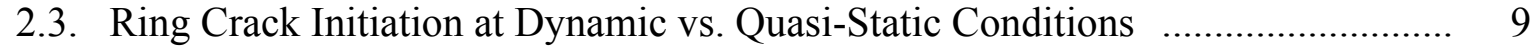

3. GAS GUN, DROP TEST, TARGET GLASS, SPHERE IMPACTERS, AND SABOT 9

3.1. Gas Gun Description ................................................................................ 9

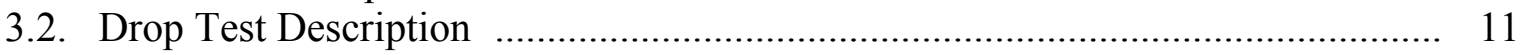

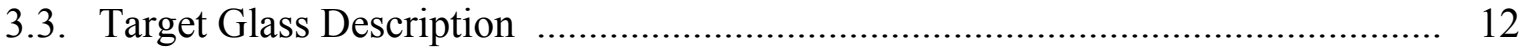

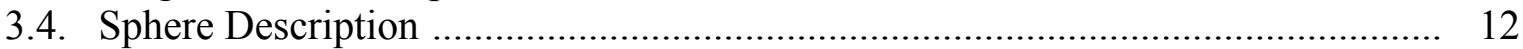

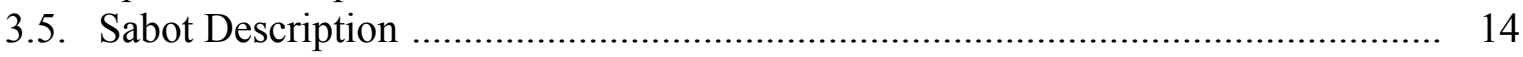

4. EXPERIMENTAL PROCEDURE .............................................................. 15

4.1. Gas Gun Calibration, Drop Test Calibration, and Unit Conversions ................. 15

4.2. Gas Gun Impact Test Procedure ............................................................... 17

4.3. Drop Impact Test Procedure .................................................................. 18

4.4. Quasi-Static Indentation ......................................................................... 19

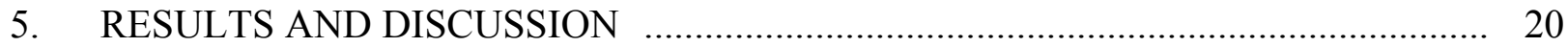

5.1. Impact Response ............................................................................ 20

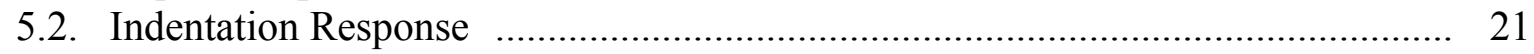

5.3. Ring Crack Initiation Force - Quasi-Static vs. Impact ................................ 22

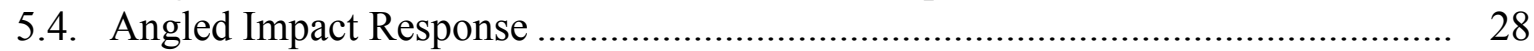

5.5. Location Dependent Indentation Response ................................................ 29

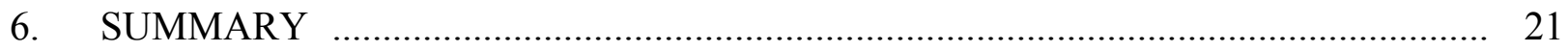

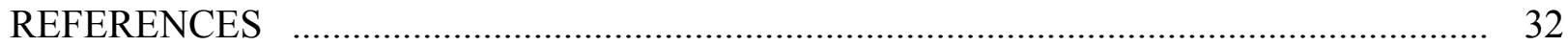

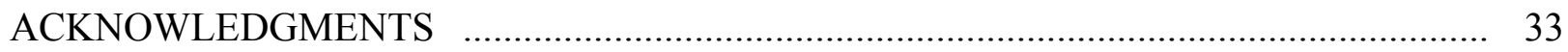

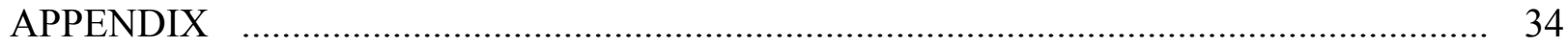




\section{LIST OF FIGURES}

Figure

Page

1. Gas gun assembly for low velocity ball impact testing. ..................................... 10

2. Illustration of velocity measurement design. ...................................................... 10

3. Top view showing end of barrel (left), velocity measurement device, and target glass (right of circular cut-out).

4. Drop test setup using the velocity measurement system, cutout showing impact area with target glass below.

5. Spheres used for impact testing (from left to right): borosilicate (BS) glass, soda-lime silicate $(\mathrm{SLS})$ glass, silicon nitride $\left(\mathrm{Si}_{3} \mathrm{~N}_{4}\right)$, alumina $\left(\mathrm{Al}_{2} \mathrm{O}_{3}\right)$, zirconia $\left(\mathrm{ZrO}_{2}\right)$, steel (carbon), and steel (chrome)

6. Gas gun pressure and resulting velocity.

7. Relationship between drop height of spheres, resulting measured velocity, and resulting impact velocity corrected for continued acceleration due to gravity below velocity measurement system.

8. Velocity conversions between $\mathrm{m} / \mathrm{s}, \mathrm{mph}$, and $\mathrm{ft} / \mathrm{s}$.

9. Schematic drawing of the ring crack initiation test configuration. An acoustic emission sensor was used to detect an acoustic event that was then linked to the ring crack initiation force. Target material is Borofloat BS glass.

10. RCIF as a function of sphere material elastic modulus for $12.7 \mathrm{~mm}$ diameter spheres. Shown RCIF values from indentation are averages and those for impact.. testing are minimum values.

11. RCIF as a function of Dundurs Parameter for $12.7 \mathrm{~mm}$ diameter spheres. Shown RCIF values from indentation are averages and those for impact testing are minimum values.

12. Normalized RCIF as a function of sphere material elastic modulus. The estimated RCIF values are based on the following material-ball-diameter combinations: BS:12.70mm, SLS:13.79mm, Chrome Steel:19.73mm, Carbon Steel:19.79mm, $\mathrm{ZrO} 2: 20.02 \mathrm{~mm}$, Si3N4:21.35mm, and A12O3:21.84mm. 


\section{LIST OF FIGURES (Continued)}

13. Normalized RCIF as a function of Dundurs Parameter. The estimated RCIF values are based on the following material-ball-diameter combinations: BS: $12.70 \mathrm{~mm}$, SLS:13.79mm, Chrome Steel:19.73mm, Carbon Steel:19.79mm, ZrO2:20.02mm,

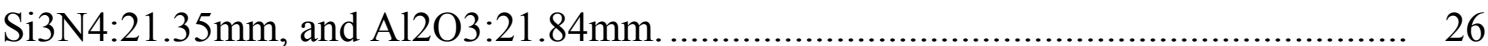

14. Relationship of kinetic energy and ring crack initiation force ................................. 27

15. Relationship of kinetic energy and ring crack initiation force. Companion figure

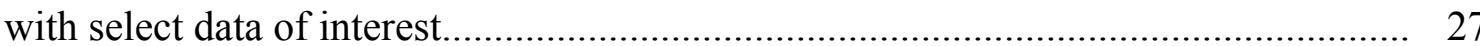

16. Weibull distribution of angled impact response. ............................................... 29

17. RCIF of silicon nitride indenter on BS glass at approximate locations.

Red is lowest value, violet is highest value. 


\section{LIST OF TABLES}

Table

Page

I. Data collection parameters for velocity recording software. ............................. 11

II. Diameter, mass, and density of materials for sphere impact testing. ....................... 13

III. Elastic properties, constant contact area diameter, and actual ball diameters. ......... 14

IV. Estimated ring crack initiation force from impact testing responses using $12.7 \mathrm{~mm}$

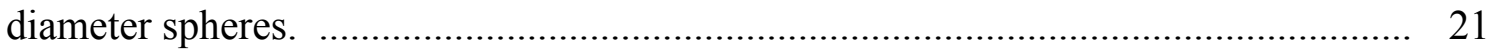

V. Estimated ring crack initiation force from impact testing responses after diameter normalization according to Eq. 10.

VI. Ring crack initiation force (RCIF) from quasi-static spherical indentation testing using $12.7 \mathrm{~mm}$ diameter spheres.

VII. Ring crack initiation force (RCIF) from quasi-static spherical indentation testing after diameter normalization according to Eq. 10.

VIII. Estimated ring crack initiation force from angled impact testing responses. 28 


\section{EXECUTIVE SUMMARY}

This report summarizes US Army TARDEC sponsored work at Oak Ridge National Laboratory (ORNL) involving low velocity $(<30 \mathrm{~m} / \mathrm{s}$ or $<65 \mathrm{mph}$ ) ball impact testing of Borofloat borosilicate glass, and is a follow-up to a similar study completed by the authors on Starphire soda-lime silicate glass last year. The response of the borosilicate glass to impact testing at different angles was also studied. The Borofloat glass was supplied by the US Army Research Laboratory and its tin-side was impacted or indented. The intent was to better understand low velocity impact response in the Borofloat. Seven sphere materials were used whose densities bracket that of rock: borosilicate glass, soda-lime silicate glass, silicon nitride, aluminum oxide, zirconium oxide, carbon steel, and a chrome steel. A gas gun or a ball-drop test setup was used to produce controlled velocity delivery of the spheres against the glass tile targets. Minimum impact velocities to initiate fracture in the Borofloat were measured and interpreted in context to the kinetic energy of impact and the elastic property mismatch between the the seven sphere-Borofloat-target combinations.

The primary observations from this low velocity $(<30 \mathrm{~m} / \mathrm{s}$ or $<65 \mathrm{mph})$ testing were:

- BS glass responded similarly to soda-lime silicate glass when spherically indented but quite differently under sphere impact conditions.

- Frictional effects contributed to fracture initiation in BS glass when it spherically indented. This effect was also observed with soda-lime silicate glass.

- The force necessary to intiate fracture in BS glass under spherical impact decreases with increasing elastic modulus of the sphere material. This trend is opposite to what was observed with soda-lime silicate glass. Friction cannot explain this trend and the authors do not have a legitimate explanation for it yet.

- The force necessary to initiate contact-induced fracture is higher under dynamic conditions than under quasi-static conditions. That difference decreases with increasing elastic modulus mismatch between the sphere material and borosilicate This trend was opposite in soda-lime silicate glass. 
- Fracture in borosilicate glass occurs at lower velocities (i.e., easier) at $24^{\circ}$ than at $0^{\circ}$ (orthogonal) and $46^{\circ}$ of impact for the same probability of failure. Though not analyzed yet, this suggests that a convolution of kinetic energy and friction is contributing to that trend.

- There is a subtle indication there was intra-tile differences in spherical indentation RCIF. This likely is not a material property nor exclusive to borosilicate glass, rather, it is a statistical response of a combination of local, surface-located flaw and imposed tensile stress. Understanding of the surface flaw population and flaw positioning can likely enable prediction of spherical indentation RCIF.

- Contact-induced fracture did not initiate in the Borofloat BS for impact kinetic energies up to $\sim 20 \mathrm{~mJ}$. For kinetic energies between $\sim 20-150 \mathrm{~mJ}$, fracture sometimes initiated. Contact-induced fracture would always occur for impact energies $>150 \mathrm{~mJ}$. The energy values, and their boundaries, were much lower for BS glass than they were for soda-lime silicate glass. 


\section{INTRODUCTION}

The impact of rock onto glass or transparent windshields is somewhat of a common issue with vehicles. A rock can come in contact with the windshield by multiple means including being kicked up by another passing vehicle. Impact velocities will be in the range of the speed that the vehicles are moving at. When a rock impacts the glass windshield, one of two things will occur; either the glass will elastically respond and no damage is initiated or it will be permanently damaged (e.g., chipping or cracking). Such permanent damage can cause overall weakening of the window, or affect the optical properties of the glass, or both. By studying and quantifying the effect of rock impact on glass the potential is established to improve resistance to the onset of undesirable permanent damage.

The meaning of the word "rock" can be quite ambiguous from a technical perspective. Rocks obviously can have different geometries (e.g., sizes and shapes) and compositions (e.g., densities and other material properties such as elastic modulus). Rocks generally have unsymmetrical shapes with many edges. When a rock strikes a glass, one of many possible complicated and unpredictable loading scenarios can result based on its geometry. It therefore can be difficult to assess a window's (i.e., target's) impact resistance when the impactor (i.e., rock or stone) can have so many independent parameters.

A sphere can be used to lessen the complexity of the event of a rock striking a glass target. A sphere of given size or diameter, density, and other physical properties can mimic or bracket those of a rock. The area and impact response of the target will be the same no matter what part of the sphere impacts it. This removes the unpredictable randomness of multiple edges and rotations of rock impact from the experiment. As we will show, it produces greater depth of understanding of the target and target material response. Additionally, sphere impact testing enables the use of established and simple Hertzian analytical modeling and subsequent interpretations. Ultimately though, an improved resistance to damage initiation with a spherical impact translates to an increased resistance to damage from an actual rock strike. 
Last year the authors completed a study in which they evaluated the sphere impact of a soda-lime silicate glass [1]. In it, it was found that: frictional effects contribute to fracture initiation, spheres with a lower elastic modulus required less force to initiate fracture than spheres with a higher elastic modulus, fracture sometimes initiated for kinetic energies between $\sim 150-1100 \mathrm{~mJ}$, however, it tended to occur when lower elastic modulus spheres were impacting it, and the force necessary to initiate contact-induced fracture is higher under dynamic or impact conditions than it is under quasi-static indentation conditions.

Interest existed to learn if transparent armor-grade borosilicate (BS) glass would respond similarly, so in the present study, the sphere impact response of BS glass was examined at velocities up to $\sim 30 \mathrm{~m} / \mathrm{s}(\sim 65 \mathrm{mph})$. Seven different ball materials were used for the impact testing and were chosen because their range of densities bracket realistic rock densities. It is known the elastic property mismatch between a spherical indenter and target material will affect the force at which Hertzian ring cracking initiates in the target because of friction [1,2]. It was anticipated that the amount of kinetic energy of impact (related to sphere material density and impact velocity) would dictate the response of the BS targets.

\section{BASICS OF SPHERICAL IMPACT}

\subsection{Estimating Impact Force from Impact Velocity}

When a sphere impacts a target the amount of stress is determined by the impulse and the amount of contact area the force is acting on [3]. For spherical or Hertzian contact loading, and assuming frictionless contact (as classical Hertzian analysis inherently does), the stress, $\sigma_{\text {rad-max }}$, required to initiate ring cracking can be determined using

$$
\sigma_{r a d-\max }=\frac{1-2 v}{2 \pi} \frac{R C I F}{a^{2}},
$$

where $R C I F$ is the ring crack initiation force, $v$ is Poisson's ratio of the target material, and $a$ is the contact radius at the applied $R C I F$. The contact radius is determined using 


$$
a=\left(\frac{3}{4} k \cdot R C I F \cdot R\right)^{1 / 3}
$$

where $\mathrm{R}$ is the sphere radius, and

$$
k=\frac{1-v_{s}^{2}}{E_{s}}+\frac{1-v_{t}^{2}}{E_{t}},
$$

where $E$ is the Young's modulus, and subscripts $s$ and $t$ represent the sphere and target, respectively.

At rock strike velocities, the velocity of impact is (or may be) known but not the associated applied force. Knight et al. [4] developed a relationship to calculate force from impact velocity by equating the kinetic energy of the sphere before impact to that of the total work, or

$$
\frac{1}{2}\left(\frac{4}{3} \pi \rho R^{3}\right) V^{2}=\int_{0}^{Z_{M a x}} P(z) d z,
$$

where $\rho$ is the density of the sphere, $V$ is the velocity of the sphere, and $z$ is calculated by

$$
z=\frac{a^{2}}{R}
$$

This allows for the estimation of the maximum force, $P_{\max }$, from a dynamic impact as described by Timoshenko and Goodier [5] or

$$
P_{\text {Max }}=\left(\frac{5}{3} \pi \rho\right)^{3 / 5}\left(\frac{3}{4} k\right)^{-2 / 5} V^{6 / 5} R^{2}
$$


If the impact initiates a ring crack, then $P_{\operatorname{Max}}$ in Eq. 6 can be equated to the ring crack initiation force $(R C I F)$, or

$$
R C I F=P_{M a x}=\left(\frac{5}{3} \pi \rho\right)^{3 / 5}\left(\frac{3}{4} k\right)^{-2 / 5} V^{6 / 5} R^{2} .
$$

The calculated impact $R C I F$ using Eq. 7 can then be compared to the $R C I F$ measured by quasistatic spherical indentation testing. Note that RCIF in Eq. 7 is independently related to sphere density $(\rho)$ and the elastic properties of the sphere and target (i.e., $k$ ).

It should be noted that the above equations are valid provided all deformation is linear elastic. If plastic or permanent deformation were to occur prior to ring crack initiation in either the sphere or target, then this introduces a violation of those assumptions and a level of complexity in the stress analysis that is beyond the scope of this report. Knight et al. [4] saw this Hertzian theory assumption break down with steel spheres impacting soda-lime-silicate glass, and as will be presented later in this report, the effects of the violation of that assumption was observed in the present study too for steel spheres.

\subsection{Comparing Different Sphere Materials}

Under contact conditions, spheres of different material will elastically deform differently when pushed against the same target material with the same applied force. That is because those sphere materials have different elastic properties and therefore will exhibit different Poisson's

effect responses. While the same sphere diameter $(12.7 \mathrm{~mm})$ was used in all tests in the present study, ideally, to perform contact response studies involving different sphere materials, diameters should be used in context to the sphere material elastic properties so that the same contact area (and contact stress) are produced for the same applied compressive force for each sphere material. This is important because it enables a confident comparison between ring crack initiations generated by spheres made from dissimilar materials, namely, the target material should ring crack at the same applied compressive force with [sphere] materials of these two radii if there is a sustained frictionless Hertzian contact and if both the indenter and target 
material remain linearly elastic up to this force [2]. However, it is exorbitantly expensive to acquire custom-diameter spheres, so this project focused on the use of the same diameter sphere, and then use those results with classical Hertzian theory to project the target performance against other diameter spheres.

The necessary sphere sizes for dissimilar materials can be calculated by using the analysis of Johnson, et al. [6], namely

$$
R_{1}\left[\frac{1-v_{1}}{G_{1}}+\frac{1-v_{t}}{G_{t}}\right]=R_{2}\left[\frac{1-v_{2}}{G_{2}}+\frac{1-v_{t}}{G_{t}}\right]
$$

or

$$
\frac{R_{2}}{R_{1}}=\frac{\frac{1-v_{1}}{G_{1}}+\frac{1-v_{t}}{G_{t}}}{\frac{1-v_{2}}{G_{2}}+\frac{1-v_{t}}{G_{t}}}
$$

where $R$ is sphere radius, $v$ is Poisson's ratio, and $G$ is shear modulus with subscripts 1,2 and $t$ representing sphere materials 1 and 2 , and the target material, respectively. The target material in this study was Borofloat BS glass tile and material $l$ was chosen to be the BS sphere material because of its almost identical properties to the target material. With these designations, the calculated value of $\mathrm{R}_{2}$ will result in the necessary sphere size for a given material (and its elastic properties) to produce the same contact radius as the BS sphere at a given force.

Even though the same sphere diameter was used in all tests, their produced impact conditions can still be correlated by developing a ratio of force, contact area, and stress using Eq. 1. With the known ring crack initiation stress, the force needed to produce the same stress with the constant contact radius, Eq. 2, (calculated using the sphere radius from Eq. 8) the normalized stress can be determined according to, 


$$
\frac{1-2 v}{2 \pi} \frac{R C I F_{A C T}}{a_{A C T}^{2}}=\frac{1-2 v}{2 \pi} \frac{R C I F_{N O R M}}{a_{N O R M}^{2}}
$$

which can be simplified to

$$
\frac{P_{A C T}}{a_{A C T}^{2}}=\frac{P_{N O R M}}{a_{N O R M}^{2}} \text {. }
$$

Equation 10 allows for a normalized RCIF, $\mathrm{P}_{\mathrm{NORM}}$, to be calculated and compared.

To represent this mismatch of elastic properties between the target and sphere, the Dundurs parameter, $\beta$, is a useful concept to utilize. $\beta$ is useful because it describes both the magnitude and direction of the elastic modulus mismatch between the contact pair. A positive $\beta$ defined here means the sphere's elastic properties produce greater stiffness than that of the target material while a negative $\beta$ means the target is stiffer than the sphere. The sign of $\beta$ also describes if the sphere or target is restricting the movement of the other under shear traction loading. $\beta$ can be calculated from [7]

$$
\beta=\frac{\frac{1-2 v_{t}}{G_{t}}-\frac{1-2 v_{s}}{G_{s}}}{2\left(\frac{1-v_{t}}{G_{t}}-\frac{1-v_{s}}{G_{s}}\right)}
$$

where $v$ is Poisson's ratio, and $G$ is shear modulus with subscripts $s$ and $t$ representing the sphere and target, respectively.

Using the normalized diameters and forces from Eq. 10, the RCIF as a function of elastic properties and Dundurs Parameter was examined in this study. As will be shown, elastic property mismatch between the sphere and target material was found to affect RCIF response in the target BS glass. That dependence in turn illustrates that frictional traction between the sphere and target glass is affecting Hertzian fracture initiation. 


\subsection{Ring Crack Initiation at Dynamic vs. Quasi-Static Conditions}

The effects of the mismatch of elastic properties between the sphere and target on ring crack initiation (i.e., fracture initiation) have not been systematically considered in (dynamic) sphere impact even though they are well established in spherical indentation (quasi-static) testing. Quasi-static indention testing, when teamed with acoustic emission detection, can easily identify the RCIF. RCIF is not so easy to detect during real-time sphere impact testing, but velocity is. By using Eq. 7, the RCIF of ball impact testing can be estimated for different sphere materials by identifying the velocity at which ring crack initiations (a dynamic RCIF) and compared to RCIF responses measured quasi-statically with spherical indentation. A difference in RCIF response will be indicative of rate-effects affecting the dynamic RCIF.

As will be shown, a rate-dependence on sphere impact RCIF was observed; namely, higher forces were required to initiate ring cracking under impact conditions than for spherical indentation. But unlike for soda-lime silicate glass [1], any contributing role of friction on the RCIF with the BS glass either did not exist or was not obvious.

\section{GAS GUN, DROP TEST, TARGET GLASS, SPHERE IMPACTERS, AND SABOT}

Depending on the sought impact velocity, either a gas gun system (for velocities $>8 \mathrm{~m} / \mathrm{s}$ ) or a ball drop test system $(<8 \mathrm{~m} / \mathrm{s})$ was used. Descriptions of both follow along with descriptions of the target glass, the spheres, and the sabot for gas gun testing.

\subsection{Gas Gun Description}

A gas gun system was used. The air supply and barrel of the gas gun is shown in Fig. 1. The system uses compressed air controlled to predetermined pressure, which is then rapidly released via a regulator into a barrel. The barrel is preloaded with a sphere held by a sabot and the released air propels them both towards the glass sample. At the end of the muzzle the sabot is stopped propelling the sphere toward the glass target. 


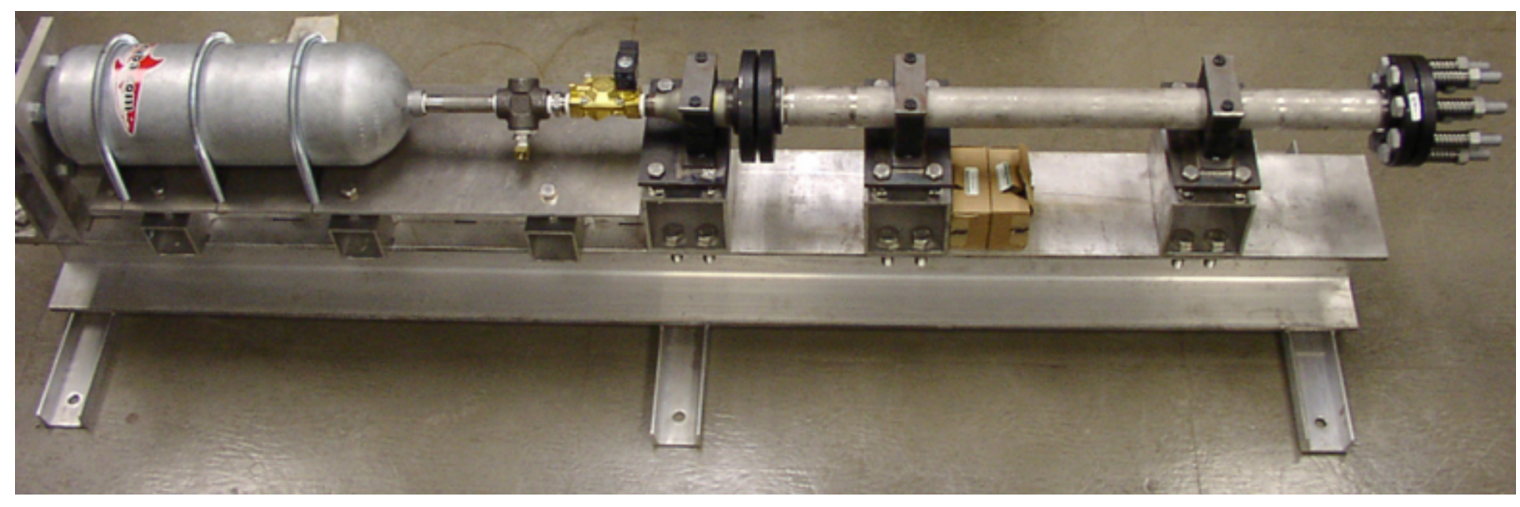

Figure 1. Gas gun assembly for low velocity ball impact testing.

The sphere passes through a parallel beam laser detection system, illustrated in Fig. 2. The laser beams are 100-mm-spaced and the sphere's time-of-flight is measured. The parallel laser beams were oriented vertically so the projectile path of the sphere would interfere with the laser regardless its arch. The muzzle end, glass target, and general impact area are enclosed in plastic to maintain safe operating conditions. The velocity measurement system and impact area can be seen in Fig. 3.

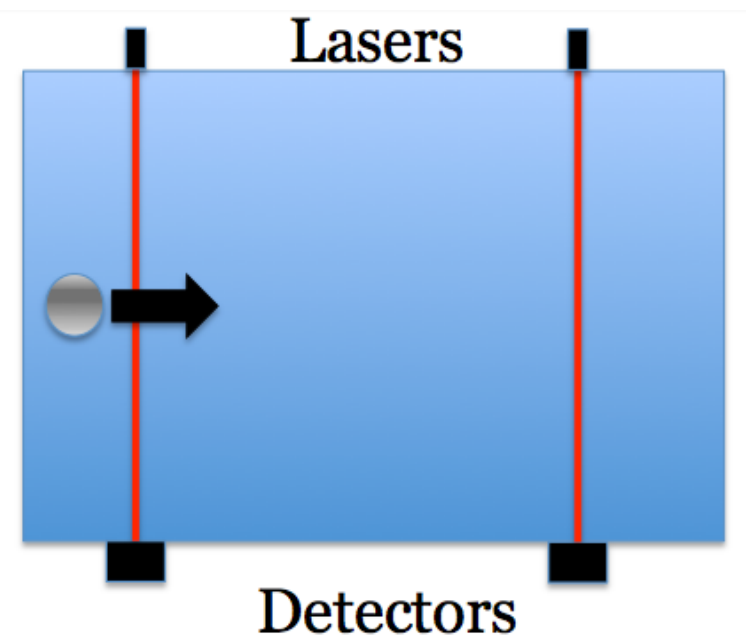

Figure 2 - Illustration of velocity measurement design. 


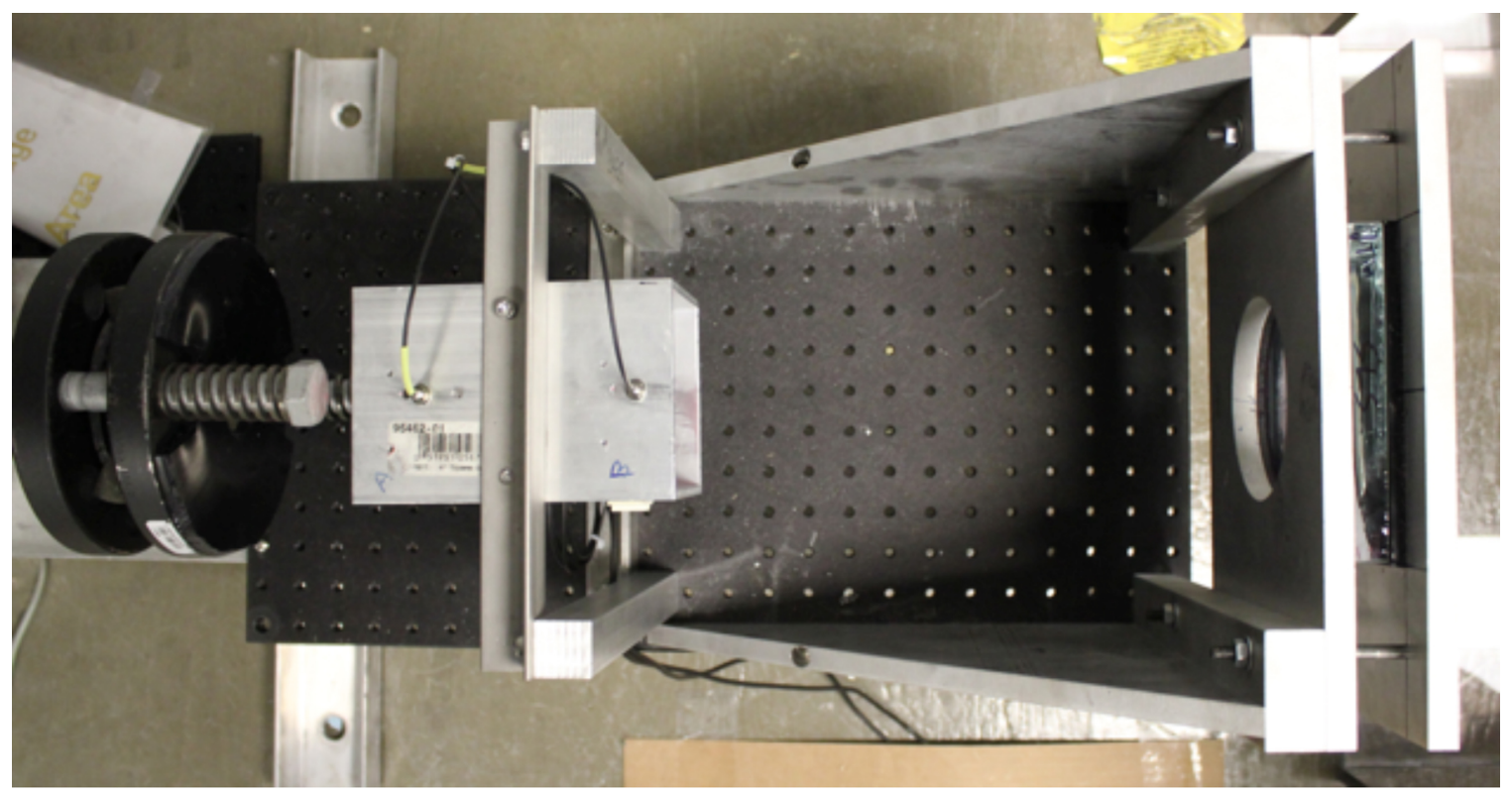

Figure 3. Top view showing end of barrel (left), velocity measurement device, and target glass (right of circular cut-out).

The velocity was recorded using an in-house developed LabView software program and a high-speed data acquisition card (National Instruments, Austin, TX). The time-of-flight data were collected with the parameters listed in Table 1.

Table I. Data collection parameters for velocity recording software.

\begin{tabular}{|c|c|}
\hline Minimum Sample Rate $(\mathrm{Hz})$ & $4.0 \times 10^{4}$ \\
\hline Minimum Number of data points & 2000 \\
\hline Resolution $(\mathrm{sec})$ & $2.5 \times 10^{-5}$ \\
\hline Total Time $(\mathrm{sec})$ & 0.05 \\
\hline
\end{tabular}

\subsection{Drop Test Description}

The gas gun has a lower velocity $(\sim 8 \mathrm{~m} / \mathrm{s})$ limit due to the necessary pressure needed to eject the sphere along a straight path towards the glass target. A drop test was utilized to test ring crack initiation velocities below the lower limit of the gas gun. The drop test has a tube that allows the sphere to be controllably released from a certain height above the glass target. This 
drop test method also utilized the velocity measurement system but vertically situated below the drop tube as shown in the Fig. 4.

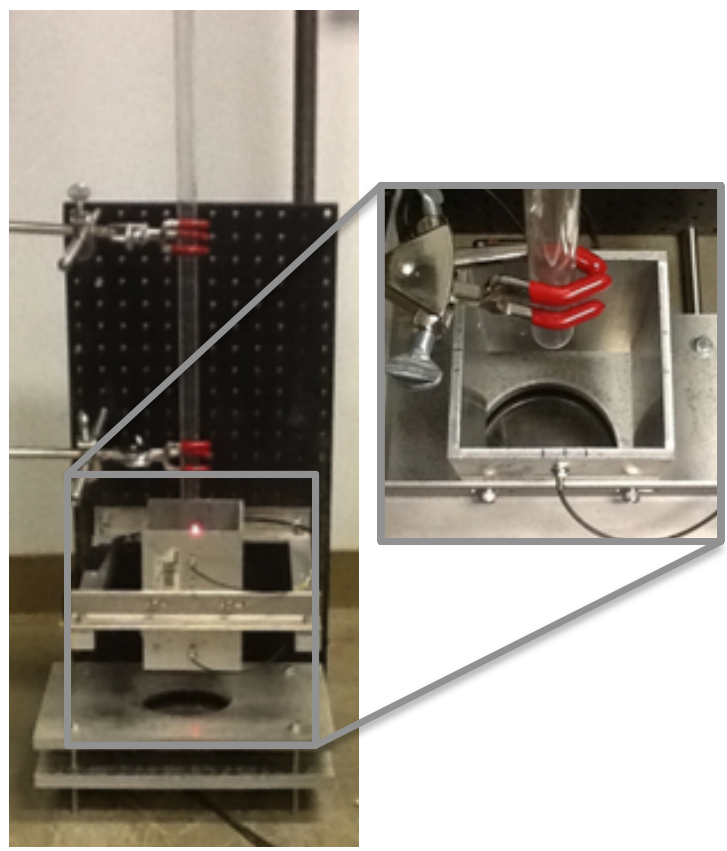

Figure 4. Drop test setup using the velocity measurement system, cutout showing impact area with target glass below.

\subsection{Target Glass Description}

The target glass tiles were a commercially available soda-lime-silicate glass (Borofloat, PPG, Pittsburgh, PA) and had nominal dimensions of $10.2 \times 10.2 \times 1.9 \mathrm{~cm}$ with a measured density of $2.22 \mathrm{~g} / \mathrm{cm}^{3}$. This glass is a tin float glass, and the tin side was tested with all tiles. The elastic modulus and Poisson's ratio were measured with resonance ultrasound spectroscopy and were $63.1 \mathrm{GPa}$ and 0.180 , respectively. A target glass in position can be seen in the right of Fig. 3. Detailed descriptions of many of this glass's properties and characteristics have been reported by the authors [8].

\subsection{Sphere Description}

Sphere materials were chosen with rock density in mind. The average density was measured with several rocks from the grounds of the ORNL campus and was $2.80 \mathrm{~g} / \mathrm{cm}^{3}$, but 
rock density can obviously vary from region to region. Therefore spheres with a range of material densities were chosen. Seven different sphere materials were considered. They, in order of increasing density, as listed in Table II, were a borosilicate (BS) glass, a soda lime silicate (SLS) glass, silicon nitride $\left(\mathrm{Si}_{3} \mathrm{~N}_{4}\right)$, aluminum oxide or alumina $\left(\mathrm{Al}_{2} \mathrm{O}_{3}\right)$, zirconium oxide or zirconia $\left(\mathrm{ZrO}_{2}\right), \mathrm{C} 1010$ (carbon) steel, and 52100 (chrome) steel.

A $12.7-\mathrm{mm}(0.5 \mathrm{inch})$ diameter was used in all testing and images of each are shown in Fig. 5. The spheres were purchased from commercial suppliers (Salem Ball, Canton, CT, for the BS glass, SLS glasses, and $\mathrm{ZrO}_{2}$, McMaster-Carr, Atlanta, GA, for the alumina and steels, and Cerbec, East Granby, CT, for the silicon nitride balls).

Table II. Diameter, mass, and density of materials for sphere impact testing listed in ascending order of density.

\begin{tabular}{|c|c|c|c|}
\multicolumn{1}{c}{ Material } & \multicolumn{1}{c}{$\begin{array}{c}\text { Diameter } \\
(\mathbf{c m})\end{array}$} & $\begin{array}{c}\text { Mass } \\
(\mathbf{g})\end{array}$ & $\begin{array}{c}\text { Density } \\
\left(\mathbf{g} / \mathbf{c m}^{\mathbf{3}}\right)\end{array}$ \\
\hline Borosilicate & 1.270 & 2.3869 & 2.225 \\
\hline Soda Lime Silicate & 1.270 & 2.6961 & 2.514 \\
\hline Silicon Nitride & 1.270 & 3.3890 & 3.160 \\
\hline Alumina & 1.270 & 4.1902 & 3.907 \\
\hline Zirconia & 1.270 & 6.5277 & 6.086 \\
\hline Steel (Carbon) & 1.270 & 8.3812 & 7.814 \\
\hline Steel (Chrome) & 1.270 & 8.3888 & 7.822 \\
\hline
\end{tabular}

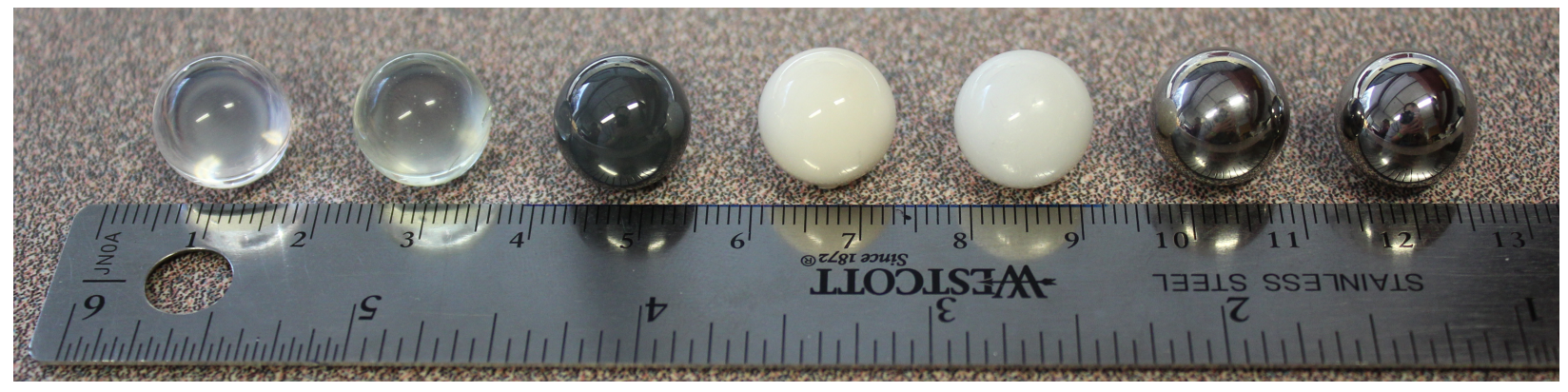

Figure 5. Spheres used for impact testing (from left to right): borosilicate (BS) glass, soda-lime silicate (SLS) glass, silicon nitride $\left(\mathrm{Si}_{3} \mathrm{~N}_{4}\right)$, alumina $\left(\mathrm{Al}_{2} \mathrm{O}_{3}\right)$, zirconia $\left(\mathrm{ZrO}_{2}\right)$, steel (carbon), and steel (chrome). 
The elastic modulus and Poisson's ratio of the spheres were determined using resonant ultrasounds spectroscopy (RUS) using a method developed by the author [9]. Their values are shown in Table III along with their calculated Dundurs parameter with respect to Borofloat BS glass (Eq. 11), and normalization diameter relative to a $12.7 \mathrm{~mm}$ diameter BS glass sphere (Eq. 8).

Table III. Elastic properties, constant contact area diameter, and actual ball diameters listed in ascending order of Dundurs Parameter value.

\begin{tabular}{|c|c|c|c|c|c|c|}
\hline $\begin{array}{l}\text { Sphere } \\
\text { Material }\end{array}$ & $\begin{array}{l}\text { Elastic } \\
\text { Modulus } \\
\text { - E - } \\
\text { (GPa) }\end{array}$ & $\begin{array}{c}\text { Poisson's } \\
\text { Ratio } \\
-v-\end{array}$ & $\begin{array}{l}\text { Shear } \\
\text { Modulus } \\
-G- \\
(\mathrm{GPa})\end{array}$ & $\begin{array}{c}\text { Eq. } 8 \\
\text { Ball Dia. } \\
-2 R- \\
(\mathrm{mm})\end{array}$ & $\begin{array}{c}\text { Used } \\
\text { Ball Dia. } \\
\text { - } 2 R- \\
\text { (mm) }\end{array}$ & $\begin{array}{c}\text { Dundurs } \\
\text { Parameter* } \\
\text { - } \beta \text { - } \\
\text { (unitless) }\end{array}$ \\
\hline Borosilicate & 62.3 & 0.20 & 25.96 & 12.70 & 12.70 & 0.007 \\
\hline Soda Lime Silicate & 73 & 0.23 & 29.67 & 13.79 & 12.70 & 0.051 \\
\hline Steel (Carbon) & 206 & 0.29 & 79.84 & 19.73 & 12.70 & 0.236 \\
\hline Steel (Chrome) & 205 & 0.32 & 77.65 & 19.79 & 12.70 & 0.245 \\
\hline Zirconia & 216 & 0.32 & 81.82 & 20.02 & 12.70 & 0.251 \\
\hline Silicon Nitride & 315 & 0.27 & 124.02 & 21.35 & 12.70 & 0.277 \\
\hline Alumina & 375 & 0.23 & 152.44 & 21.84 & 12.70 & 0.286 \\
\hline
\end{tabular}

* Calculated using Eq. 11 for the given sphere material against Borofloat BS glass target.

\subsection{Sabot Description}

A sabot was used for the gas-gun sphere shooting. The sabots were cast from a rigid polyurethane foam (FOAM-iT! ${ }^{\circledR}$ 15, Smooth-On, Inc., Easton, PA) and were formed in a shape to retain a $12.7 \mathrm{~mm}$ diameter sphere. The sabot cradles the sphere as it accelerates down the barrel of the gas-gun. At the muzzle end of the barrel the fast traveling sabot was abruptly stopped launching the sphere toward the glass sample. 


\section{EXPERIMENTAL PROCEDURE}

4.1. Gas Gun Calibration, Drop Test Calibration, and Unit Conversions

Gas Gun Calibration

The ratio of gas gun pressure to produced sphere velocity was determined in order to control the approximate velocity the sphere would hit the target. The relationship is shown in Fig. 6.

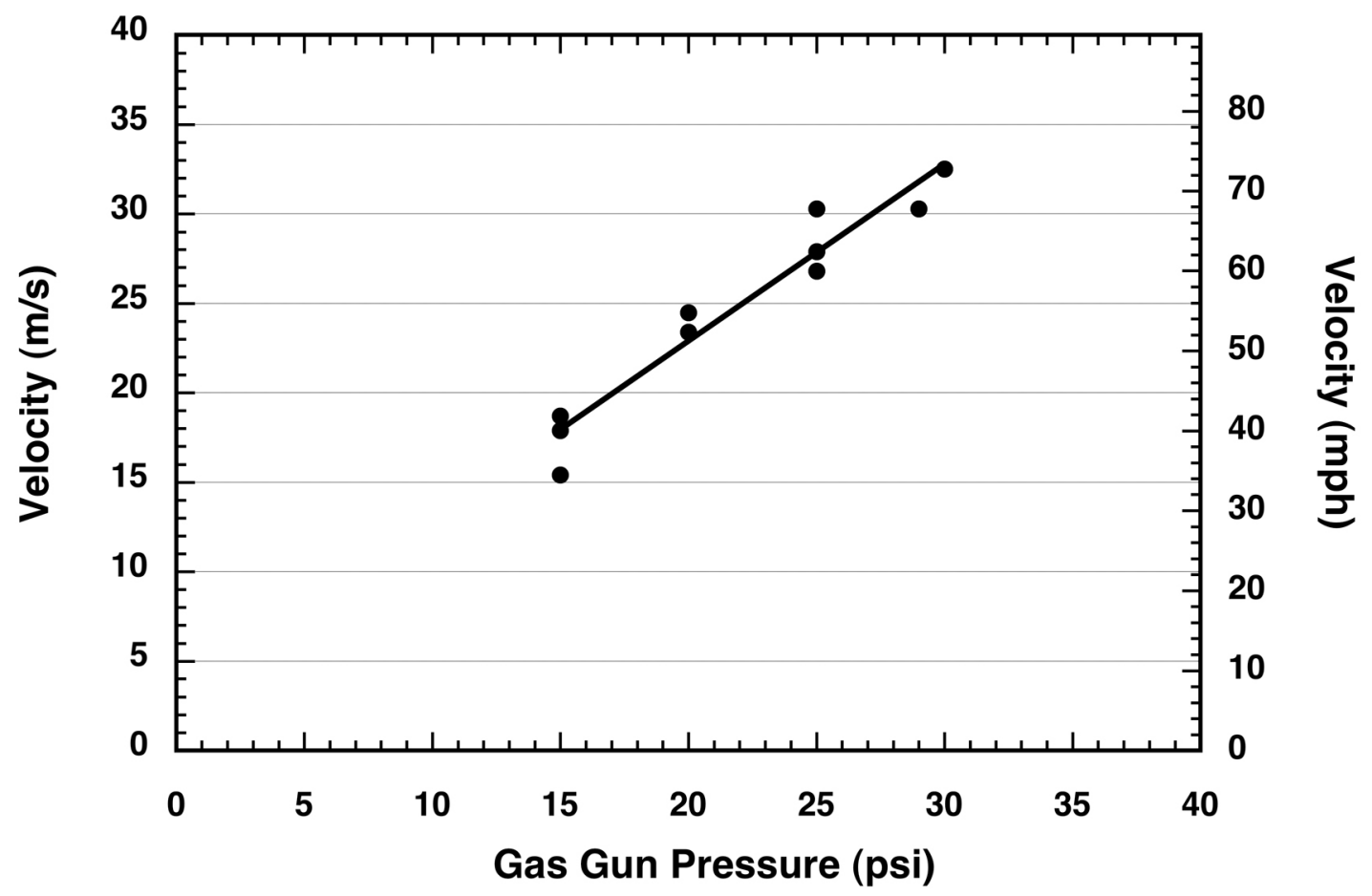

Figure 6. Gas gun pressure and resulting velocity.

The mass of the sabot was much greater than the mass of the sphere for all seven materials therefore it was assumed that all spheres launched at approximately the same velocity for a given pressure. Regardless, the sphere velocity of each launch was recorded. Occasionally 
the velocity measurement system failed to record. In those instances, the velocity was estimated using the trend shown in Fig. 6.

\section{Drop Test Calibration}

The ratio of drop height to produced sphere velocity was determined to control the approximate speed the sphere strikes the target. Simple acceleration due to gravity could not be relied upon to determine the velocity due to interference of the drop tube with the sphere while falling in case air-drag in the tube impeded the sphere's drop speed. After the sphere leaves the tube (to pass through the velocity measurement system and strike the target) the acceleration due to gravity is accounted for. The relationship between drop height and impact velocity is shown in Fig. 7. Occasionally the velocity measurement system failed to record. In those instances, the velocity was estimated using the trend shown in Fig. 7.

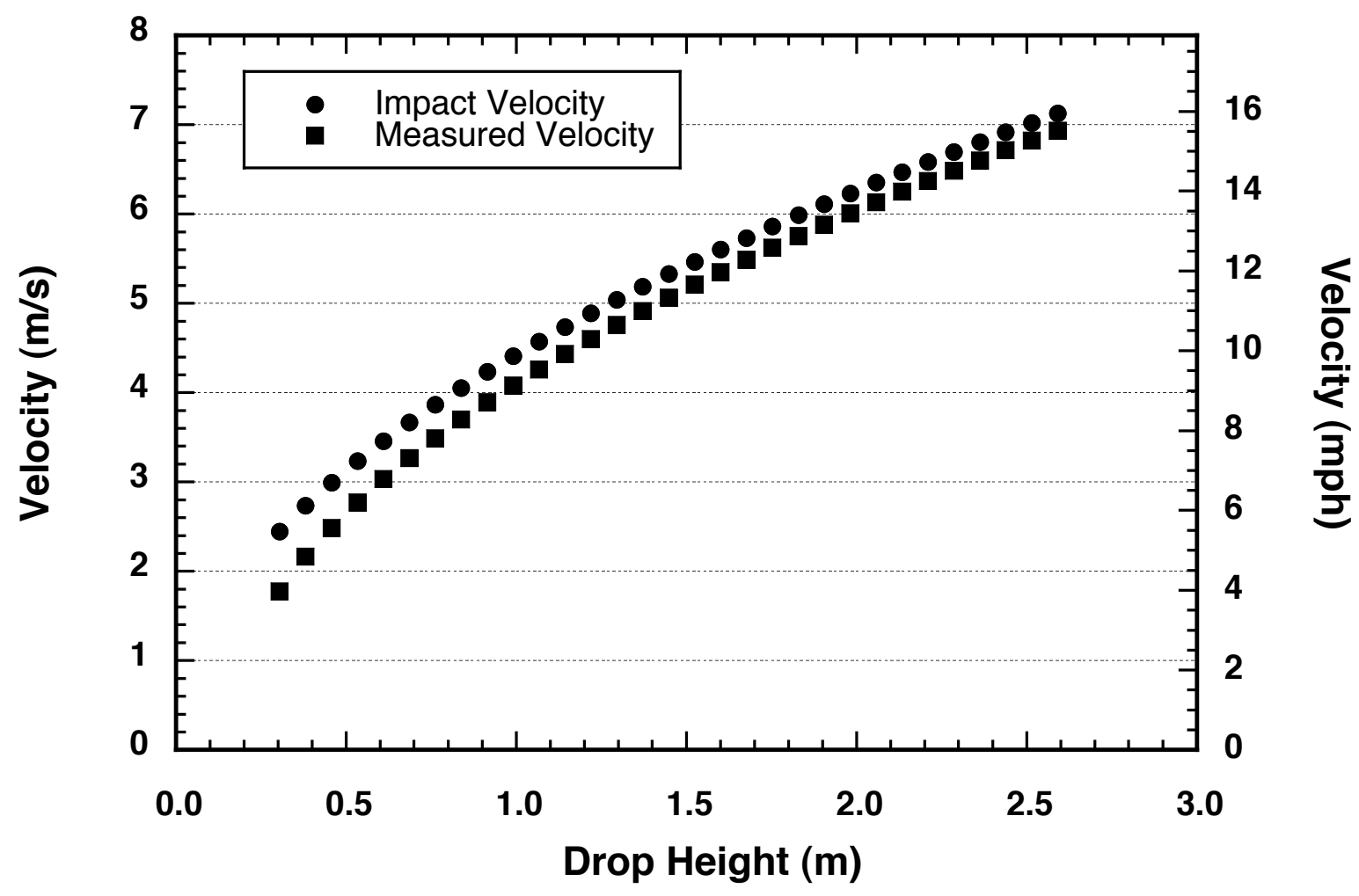

Figure 7. Relationship between drop height of spheres, resulting measured velocity, and resulting impact velocity corrected for continued acceleration due to gravity below velocity measurement system. 


\section{Unit Conversion}

Metric and English units of velocity were both used, and their unit conversions are illustrated in Fig. 8 and listed in Eqs. 12-14.

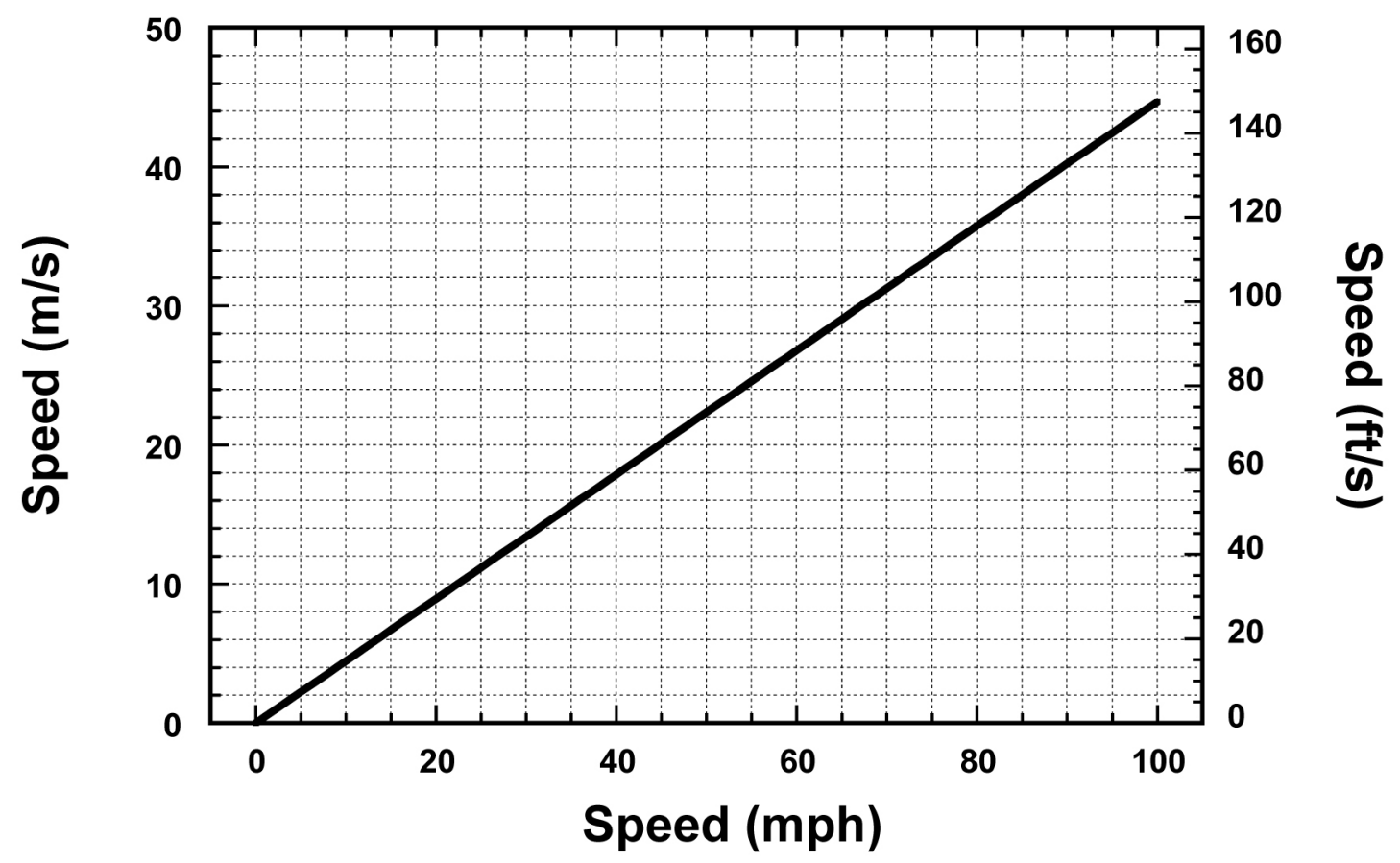

Figure 8 . Velocity conversions between $\mathrm{m} / \mathrm{s}, \mathrm{mph}$, and $\mathrm{ft} / \mathrm{s}$.

$$
\begin{gathered}
1.00 \mathrm{~m} / \mathrm{s}=3.28 \mathrm{ft} / \mathrm{s}=2.24 \mathrm{mph} \\
1.00 \mathrm{mph}=1.47 \mathrm{ft} / \mathrm{s}=0.447 \mathrm{~m} / \mathrm{s} \\
1.00 \mathrm{ft} / \mathrm{s}=0.682 \mathrm{mph}=0.305 \mathrm{~m} / \mathrm{s}
\end{gathered}
$$

\subsection{Gas Gun Impact Test Procedure}

The Borofloat BS glass tile was loaded into position in the tile holder and oriented to be struck on its tin side. The Borofloat BS glass tile was sandwiched between two medium density rubber gaskets each having 100-mm-diameter holes oriented concentrically with the 100-mm- 
diameter hole in the holders (seen at far right in Fig. 3). There is a bottom rubber gasket to keep the placement height constant and position the target glass to be struck in the approximate center of the glass tile (100-mm-diameter exposed). Four bolts were torqued to $7 \mathrm{~N} \cdot \mathrm{m}(5 \mathrm{ft} \cdot \mathrm{lb})$ to uniformly compress the rubber gaskets. The relatively thick glass, coupled with the firm gripping of their margin for the sphere impact testing, resulted in insignificant outer-fiber deflection of the tiles occurring during the impact event. In support of that, no tiles ever fractured from bending.

The sabot and sphere were loaded on the breach side of the barrel and the barrel was then connected to the air gas supply. The gas chamber was adjusted to the desired pressure using input and blow-off valve switches. With the safety shields positioned, the main valve of the gas chamber was switched open to release the compressed air into the barrel behind the sabot, thusly launching it. The velocity of the ejected sphere was recorded and the damage to the target sample optically examined with a compound optical microscope. The glass tile was reused if no crack was observed.

\subsection{Drop Impact Test Procedures}

The Borofloat BS glass tile was positioned and loaded into the tile holder and velocity measurement system identically to the gas gun as described in Section 4.2. This setup was oriented vertically under a drop test tube. A sphere was loaded into the tube at a designated height. The sphere was the released and allowed to drop freely. The velocity was measured during each drop and corrected for the free-fall acceleration between the velocity measurement system and the target. The tile was the inspected for damage. If no damage was seen the tile remained in the test setup and a higher velocity (height) was used. The crack initiation force was defined as the lowest velocity (height) at which and damage was seen (i.e., velocity necessary to initiate fracture).

To test the response of non-orthogonal or oblique impact the drop test was also performed against glass tiles angled to the strike direction path. One side of the tile was elevated a given height resulting in a tile being struck at an angle. Simply trigonometry was used to 
calculate the angle from a given height. Only $\mathrm{Si}_{3} \mathrm{~N}_{4}$ sphere material is used for this obliquity testing. All other procedure methods are kept the same as the vertically oriented drop test.

\subsection{Quasi-Static Indentation}

Quasi-static spherical indentation was performed using an electromechanical test frame. The impact RCIF was shown in Eq. 7 to be independently related to sphere density and elastic properties of the sphere and target; however, for quasi-static indentation, sphere density does not affect RCIF, so this indentation provides a means to deconvolute their effects on RCIF. A schematic of the experimental setup is shown in Fig. 9. The 12.7-mm-diameter spheres (Fig. 5) used for the impact testing were used as spherical indenters. The glass tiles used for indentation were the same target Borofloat BS glass tiles used for impact testing. The indentation was performed on the tin side of the glass just like the impact testing. A displacement rate of 0.002 $\mathrm{mm} / \mathrm{s}$ was used to compressively load the glass tile until crack initiation occurred followed by rapid unloading. Acoustic emission was continuously monitored to determine the moment of ring crack initiation and its associated compressive force. Each indentation test occurred in an undamaged portion of the Borofloat BS glass tile. At least 16 indentation tests were performed with all seven sphere materials. The BS and SLS sphere tests used a virgin ball for every indent, the carbon and chrome steel spheres were randomly rotated but reused for each test, the zirconia, silicon nitride, and alumina reused the same sphere in the same orientation for every indent. The average, standard deviation, minimum, and maximum values were calculated for each sphere material.

Based on unanticipated test results (described later) an additional test was performed to examine any evidence of location-dependent RCIF or RCIF variability on a single BS tile. Using a silicon nitride spherical indenter, a virgin tile was indented in an evenly spaced 10 by 10 array. The resulting RCIF values were mapped. 


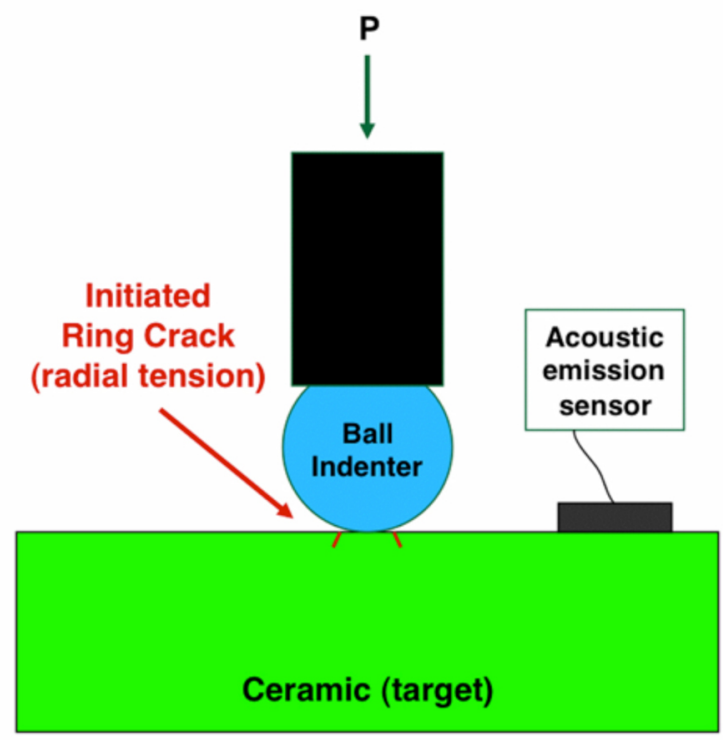

Figure 9. Schematic drawing of the ring crack initiation test configuration. An acoustic emission sensor was used to detect an acoustic event that was then linked to the ring crack initiation force. Target material is Borofloat BS glass.

\section{RESULTS AND DISCUSSION}

\subsection{Impact Response}

The minimum velocities needed to initiate ring crack initiation (i.e., fracture) in the Borofloat BS glass tiles for each of the seven sphere materials are shown in Table IV. The BS and SLS glass spheres were shot with the gas gun to produce velocities needed for ring crack initiation. However, the other five sphere materials required lower velocities as produced by the ball drop test. The complete list of tests and results are shown in Appendix I. The estimated ring crack initiation force (RCIF) values listed in Table IV were calculated using Eq. 7 with those listed velocities. The estimated ring crack initiation force (RCIF) with diameter normalization according to Eq. 10 is shown in Table V. The maximum radial tensile stress was calculated using Eq. 1. The kinetic energy was calculated using the classical formulation of $1 / 2 \bullet m \bullet V^{2}$ where $m$ is mass of the sphere. 
Table IV. Estimated ring crack initiation force from impact testing responses using $12.7 \mathrm{~mm}$ diameter spheres.

\begin{tabular}{|c|c|c|c|c|}
\hline $\begin{array}{c}\text { Sphere } \\
\text { Material }\end{array}$ & $\begin{array}{c}\text { Velocity } \\
(\mathrm{m} / \mathrm{s})\end{array}$ & $\begin{array}{c}\text { RCIF } \\
(\mathbf{N})\end{array}$ & $\begin{array}{c}\text { Maximum } \\
\text { Radial } \\
\text { Tensile Stress } \\
\text { (MPa) }\end{array}$ & $\begin{array}{c}\text { Kinetic } \\
\text { Energy } \\
(\mathrm{mJ})\end{array}$ \\
\hline BS glass & 11.4 & 3690 & 532 & 154 \\
\hline SLS glass & 12.7 & 4680 & 547 & 217 \\
\hline Carbon Steel & 3.68 & 2490 & 461 & 57 \\
\hline Chrome Steel & 3.52 & 2380 & 395 & 52 \\
\hline Zirconia & 3.87 & 2220 & 365 & 49 \\
\hline $\mathrm{Si}_{3} \mathrm{~N}_{4}$ & 3.38 & 1270 & 382 & 19 \\
\hline $\mathrm{Al}_{2} \mathrm{O}_{3}$ & 3.73 & 1620 & 489 & 29 \\
\hline
\end{tabular}

Table V. Estimated ring crack initiation force from impact testing responses after diameter normalization according to Eq. 10.

\begin{tabular}{|c|c|}
\multicolumn{1}{c}{$\begin{array}{c}\text { Sphere } \\
\text { Material }\end{array}$} & \multicolumn{1}{c}{$\begin{array}{c}\text { RCIF } \\
(\mathbf{N})\end{array}$} \\
\hline BS glass & 3690 \\
\hline SLS glass & 4950 \\
\hline Carbon Steel & 3520 \\
\hline Chrome Steel & 3420 \\
\hline Zirconia & 3010 \\
\hline $\mathrm{Si}_{3} \mathrm{~N}_{4}$ & 1700 \\
\hline $\mathrm{Al}_{2} \mathrm{O}_{3}$ & 2180 \\
\hline
\end{tabular}

\subsection{Indentation Response}

The summary statistics from the quasi-static spherical indention testing are shown in Tables VI-VII for the $12.7 \mathrm{~mm}$ diameter spheres and for the normalized spheres diameters respectively. Only ring crack initiation force is collected from this test. 
Table VI. Ring crack initiation force (RCIF) from quasi-static spherical indentation testing using $12.7 \mathrm{~mm}$ diameter spheres.

\begin{tabular}{ccc|c|c|}
\multicolumn{1}{c}{$\begin{array}{c}\text { Sphere } \\
\text { Material }\end{array}$} & $\begin{array}{c}\text { Average } \\
\text { RCIF } \\
(\mathrm{N})\end{array}$ & $\begin{array}{c}\text { Std Dev } \\
\text { RCIF } \\
(\mathrm{N})\end{array}$ & $\begin{array}{c}\text { Min } \\
\text { RCIF } \\
(\mathrm{N})\end{array}$ & $\begin{array}{c}\text { Max } \\
\text { RCIF } \\
(\mathrm{N})\end{array}$ \\
\hline BS glass & 620 & 317 & 184 & 1140 \\
\hline SLS glass & 1160 & 554 & 364 & 2460 \\
\hline $\begin{array}{c}\text { Carbon } \\
\text { Steel }\end{array}$ & 1450 & 998 & 550 & 4050 \\
\hline $\begin{array}{c}\text { Chrome } \\
\text { Steel }\end{array}$ & 1420 & 1030 & 303 & 4650 \\
\hline $\mathrm{Zirconia}^{2}$ & 920 & 471 & 353 & 1760 \\
\hline $\mathrm{Si}_{3} \mathrm{~N}_{4}$ & 600 & 349 & 253 & 1550 \\
\hline $\mathrm{Al}_{2} \mathrm{O}_{3}$ & 1200 & 624 & 564 & 2340 \\
\hline
\end{tabular}

Table VII. Ring crack initiation force (RCIF) from quasi-static spherical indentation testing after diameter normalization according to Eq. 10.

\begin{tabular}{|c|c|c|c|c|}
\hline $\begin{array}{l}\text { Sphere } \\
\text { Material }\end{array}$ & $\begin{array}{c}\text { Average } \\
\text { RCIF } \\
\text { (N) }\end{array}$ & $\begin{array}{c}\text { Std Dev } \\
\text { RCIF } \\
(\mathrm{N})\end{array}$ & $\begin{array}{l}\text { Min } \\
\text { RCIF } \\
(\mathrm{N})\end{array}$ & $\begin{array}{c}\text { Max } \\
\text { RCIF } \\
(\mathrm{N})\end{array}$ \\
\hline BS glass & 620 & 317 & 184 & 1140 \\
\hline SLS glass & 1230 & 586 & 384 & 2600 \\
\hline $\begin{array}{c}\text { Carbon } \\
\text { Steel }\end{array}$ & 2050 & 1410 & 778 & 5730 \\
\hline $\begin{array}{l}\text { Chrome } \\
\text { Steel }\end{array}$ & 2030 & 1480 & 435 & 6680 \\
\hline Zirconia & 1250 & 638 & 479 & 2380 \\
\hline $\mathrm{Si}_{3} \mathrm{~N}_{4}$ & 807 & 468 & 339 & 2080 \\
\hline $\mathrm{Al}_{2} \mathrm{O}_{3}$ & 1610 & 839 & 758 & 3150 \\
\hline
\end{tabular}

5.3. Ring Crack Initiation Force - Quasi-Static vs. Impact

Frictional effects contribute to fracture initiation in borosilicate (BS) glass when it is quasi-statically, spherically indented by the different sphere materials, as was also observed with soda-lime silicate glass [1]. This is represented by the positive slopes of the fitted lines in Figs. 
10-13 for combinations of unnormalized and normalized portrayals with elastic modulus or Dundurs Parameter. Whereas steel spheres appear to deform when used as indenters or impactors against soda-lime silicate glass [1,8], which affects ring crack initiation force, such a response was not pronounced with the testing of BS glass in this study. This difference in steel deformation response can simply be attributed to the lower indentation forces and impact velocities that were necessary for ring crack initiation in BS glass.

While BS glass responded similarly to soda-lime silicate glass with spherical indentation [1]; however, under spherical impact responds is quite differently. The slopes of the impact data in Figs. 10-13 are negative whereas they were positive for soda-lime silicate glass (an indicator of active friction effects) [1]. Friction effects therefore cannot explain this trend in BS glass and a legitimate explanation of it presently eludes the authors.

The force necessary to initiate contact-induced fracture is higher under dynamic conditions than it is under quasi-static conditions. Tillet [10], Johnson et al. [6], and the present authors [1] reported similar differences in quasi-static and dynamic sphere tests that are shown in Figs. 10-13 but they did not offer a potential explanation other than indicating it was due to a "rate effect". That difference between quasi-static and dynamic diminishes with increasing elastic modulus mismatch between the sphere material and borosilicate. This trend was opposite in soda-lime silicate glass [1]. 


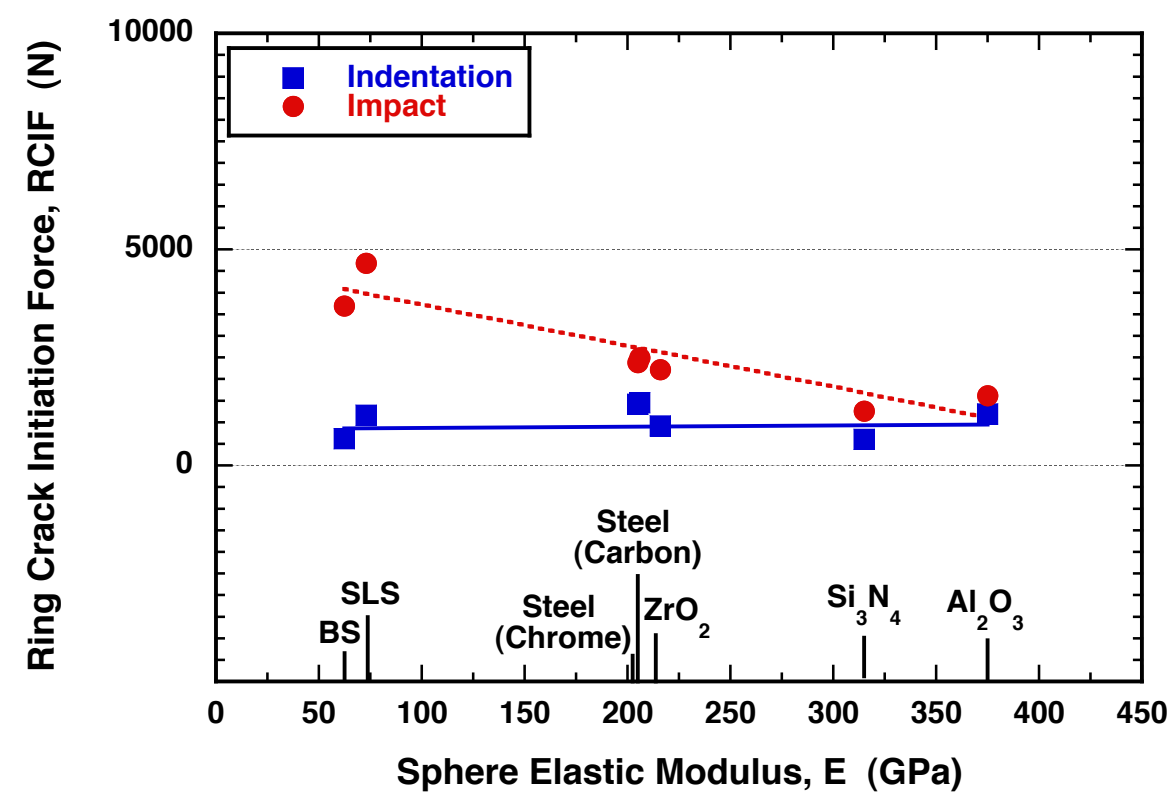

Figure 10. RCIF as a function of sphere material elastic modulus for $12.7 \mathrm{~mm}$ diameter spheres. Shown RCIF values from indentation are averages and those for impact testing are minimum values.

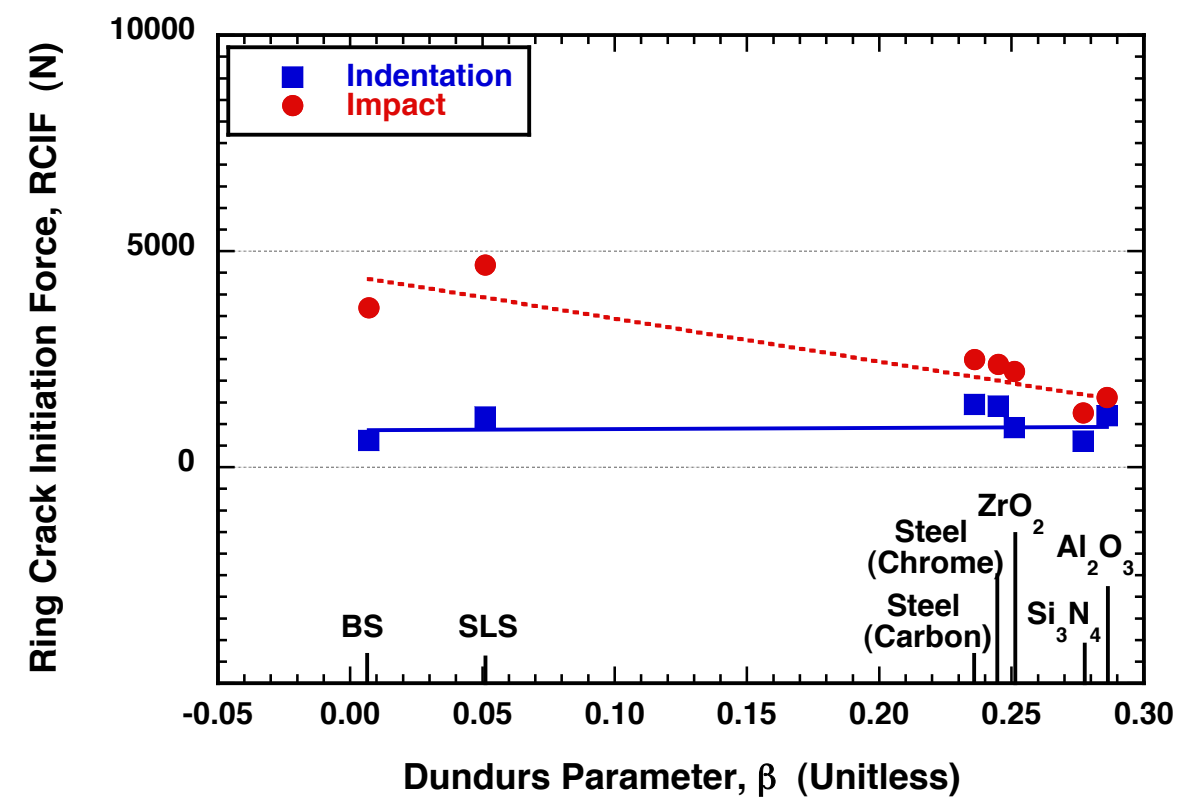

Figure 11. RCIF as a function of Dundurs Parameter for $12.7 \mathrm{~mm}$ diameter spheres. Shown RCIF values from indentation are averages and those for impact testing are minimum values. 
In order to equivalently compare the quasi-static and dynamic RCIF responses, the sphere diameters need to be normalized as listed in Table III. When those diameters are normalized, then Figs. 10-11 are transformed into what is illustrated in Figs. 12-13. The fact those fitted linear curves for the spherical indentation have positive slopes (i.e., RCIF independent of elastic properties) signifies that friction effects are contributing to the RCIF responses for both quasistatic loadings.

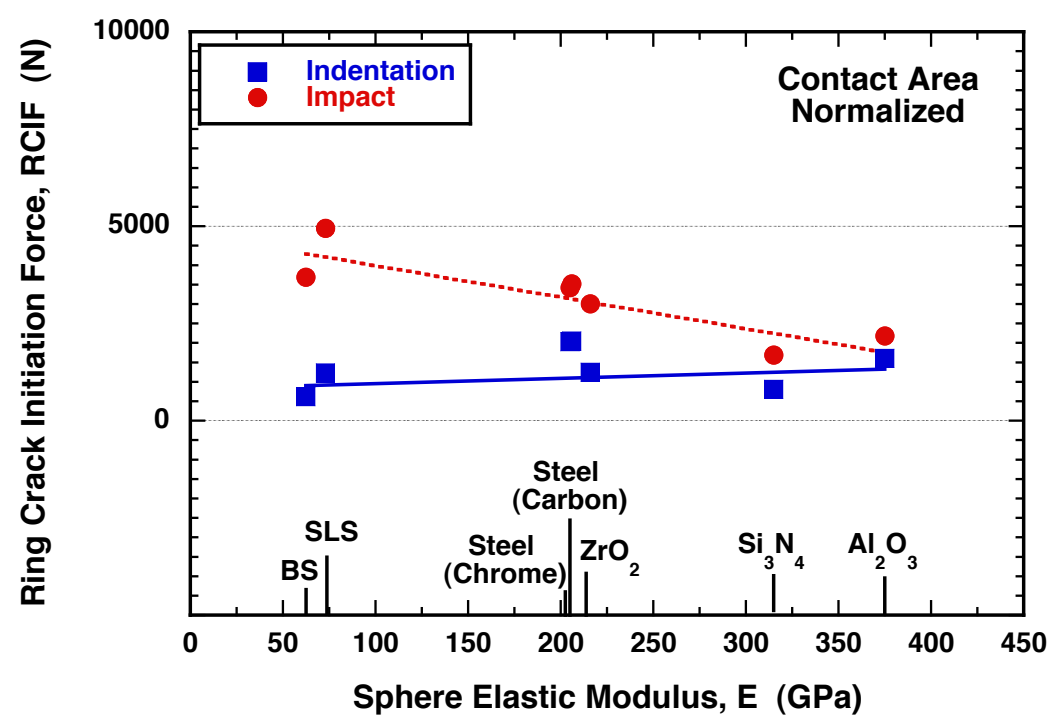

Figure 12. Normalized RCIF as a function of sphere material elastic modulus. The estimated RCIF values are based on the following material-ball-diameter combinations: BS: $12.70 \mathrm{~mm}$, SLS: $13.79 \mathrm{~mm}$, Chrome Steel:19.73mm, Carbon Steel:19.79mm, $\mathrm{ZrO}_{2}: 20.02 \mathrm{~mm}, \mathrm{Si}_{3} \mathrm{~N}_{4}: 21.35 \mathrm{~mm}$, and $\mathrm{Al}_{2} \mathrm{O}_{3}: 21.84 \mathrm{~mm}$. 


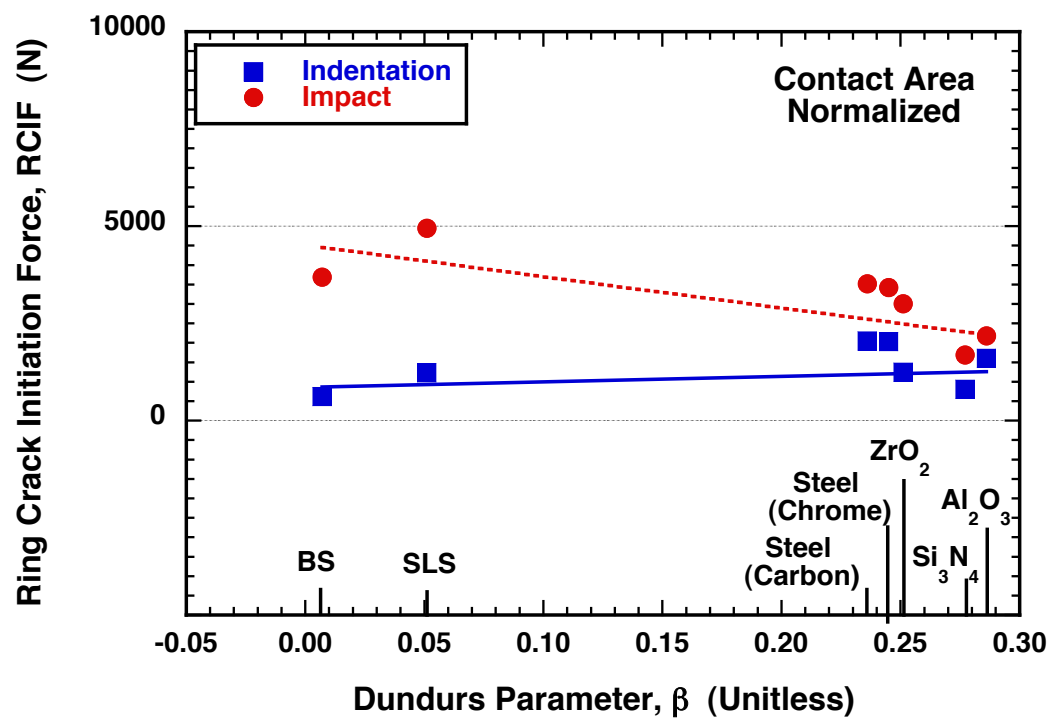

Figure 13. Normalized RCIF as a function of Dundurs Parameter. The estimated RCIF values are based on the following material-ball-diameter combinations: BS:12.70mm, SLS: $13.79 \mathrm{~mm}$, Chrome Steel:19.73mm, Carbon Steel:19.79mm, $\mathrm{ZrO}_{2}: 20.02 \mathrm{~mm}, \mathrm{Si}_{3} \mathrm{~N}_{4}: 21.35 \mathrm{~mm}$, and $\mathrm{Al}_{2} \mathrm{O}_{3}: 21.84 \mathrm{~mm}$.

The role of kinetic energy was considered too. The velocities and sphere materials listed in Appendix I were used to calculate kinetic energy $\left(1 / 2 \bullet m \bullet \mathrm{V}^{2}\right)$ and graphed as a function of each RCIF in Figs. 14-15. For kinetic energies less than about $20 \mathrm{~mJ}$, no ring cracking initiated in the BS glass. Between about 20 and $150 \mathrm{~mJ}$, ring cracking sometimes occurred depending on which sphere material did the impacting. For impact energies greater than $150 \mathrm{~mJ}$, ring crack initiation always occurred. The energy values, and their boundaries, were much lower for BS glass than they were for soda-lime silicate glass [1]. 


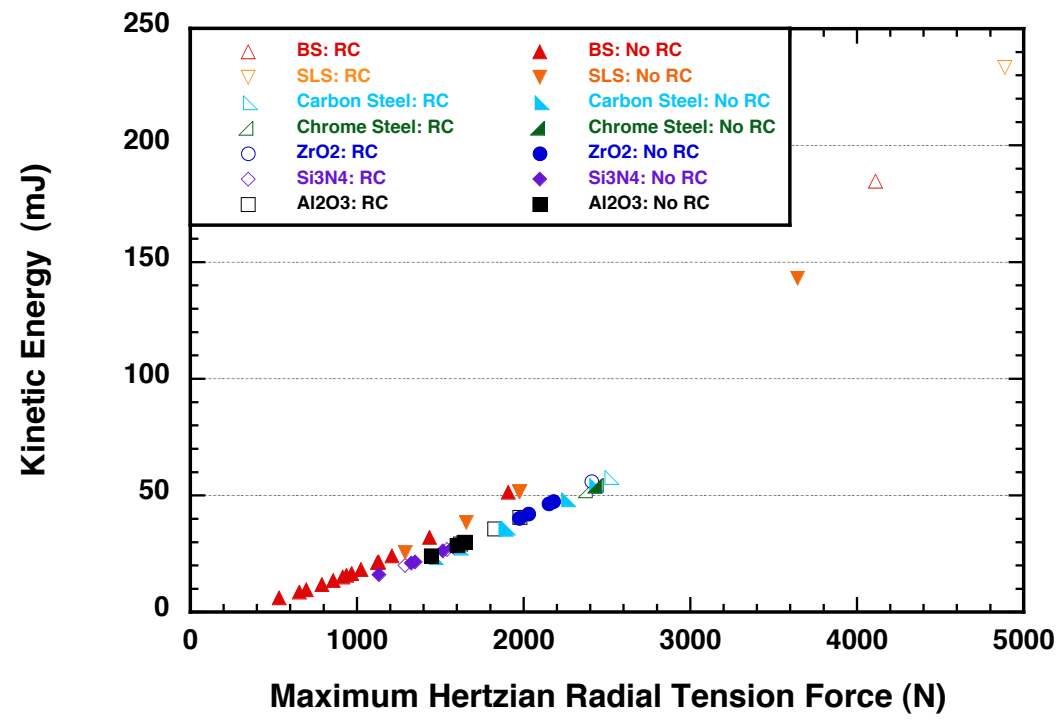

Figure 14. Relationship of kinetic energy and ring crack initiation force. Damage does not initiate in the target BS glass for energies less than about $20 \mathrm{~mJ}$, damage initiation is sphere material dependent between 20 and $150 \mathrm{~mJ}$, and the BS ring cracks for all kinetic energies greater than $150 \mathrm{~mJ}$.

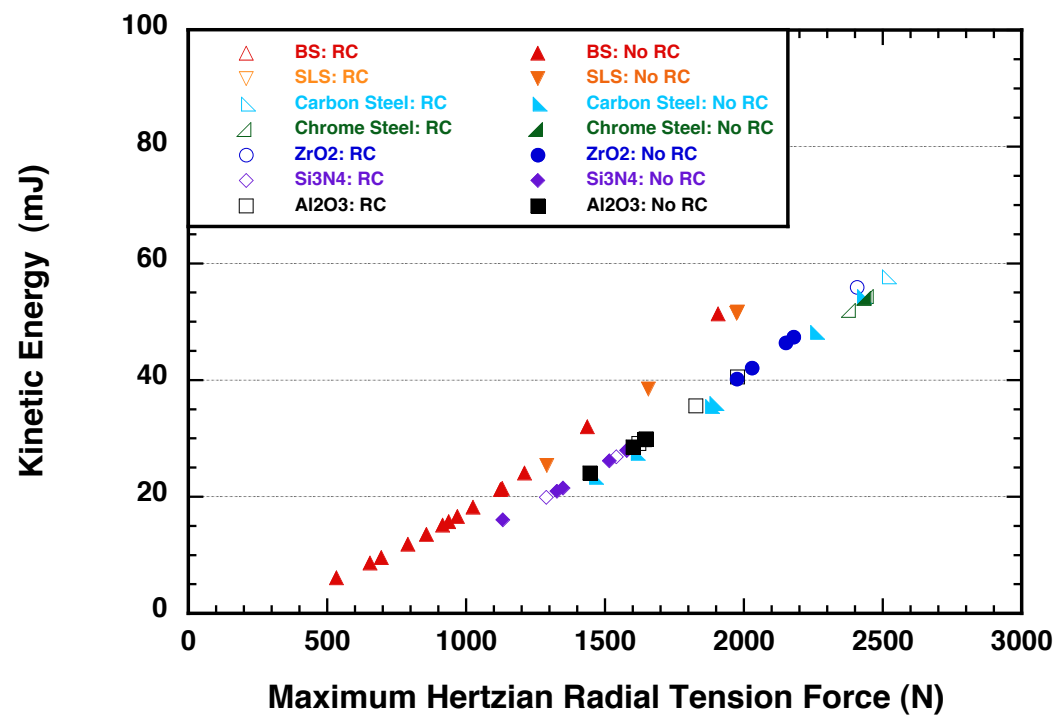

Figure 15. Relationship of kinetic energy and ring crack initiation force. Companion figure with select data of interest. 


\subsection{Angled Impact Response}

The minimum velocities needed to initiate ring crack initiation (i.e., fracture) in the Borofloat BS glass tiles struck by $\mathrm{Si}_{3} \mathrm{~N}_{4}$ at three different angles are shown in Table VIII. The values are not normalized due to only one sphere material tested. The complete list of tests and results are shown in Appendix II.

The estimated ring crack initiation force (RCIF) values listed in Table VIII were calculated using Eq. 7 with those listed velocities. The maximum radial tensile stress was calculated using Eq. 1. The kinetic energy was calculated using the classical formulation of $1 / 2 \cdot m \cdot V^{2}$ where $m$ is mass of the sphere. The probability of failure was calculated and a Weibull distribution of the data is below in Fig. 16.

Fracture in borosilicate glass occurs at lower velocities at $24^{\circ}$ than at $0^{\circ}$ (orthogonal) and $46^{\circ}$ of impact for the same probability of failure. Though not analyzed yet, this suggests that a convolution of kinetic energy and friction is contributing to that trend. However, more testing to improve upon the statistics is warranted along with additional angles of impact to better understand and confirm that trend.

Table VIII. Estimated ring crack initiation force from angled impact testing responses.

\begin{tabular}{|c|c|c|c|c|}
\hline Angle & $\begin{array}{c}\text { Velocity } \\
(\mathrm{m} / \mathrm{s})\end{array}$ & $\begin{array}{c}\text { RCIF } \\
(\mathbf{N})\end{array}$ & $\begin{array}{c}\text { Maximum } \\
\text { Radial } \\
\text { Tensile Stress } \\
\text { (MPa) }\end{array}$ & $\begin{array}{c}\text { Kinetic } \\
\text { Energy } \\
(\mathrm{mJ})\end{array}$ \\
\hline 0 & 3.38 & 1260 & 382 & 19 \\
\hline 24 & 3.01 & 1100 & 365 & 15 \\
\hline 46 & 3.91 & 1510 & 405 & 26 \\
\hline
\end{tabular}




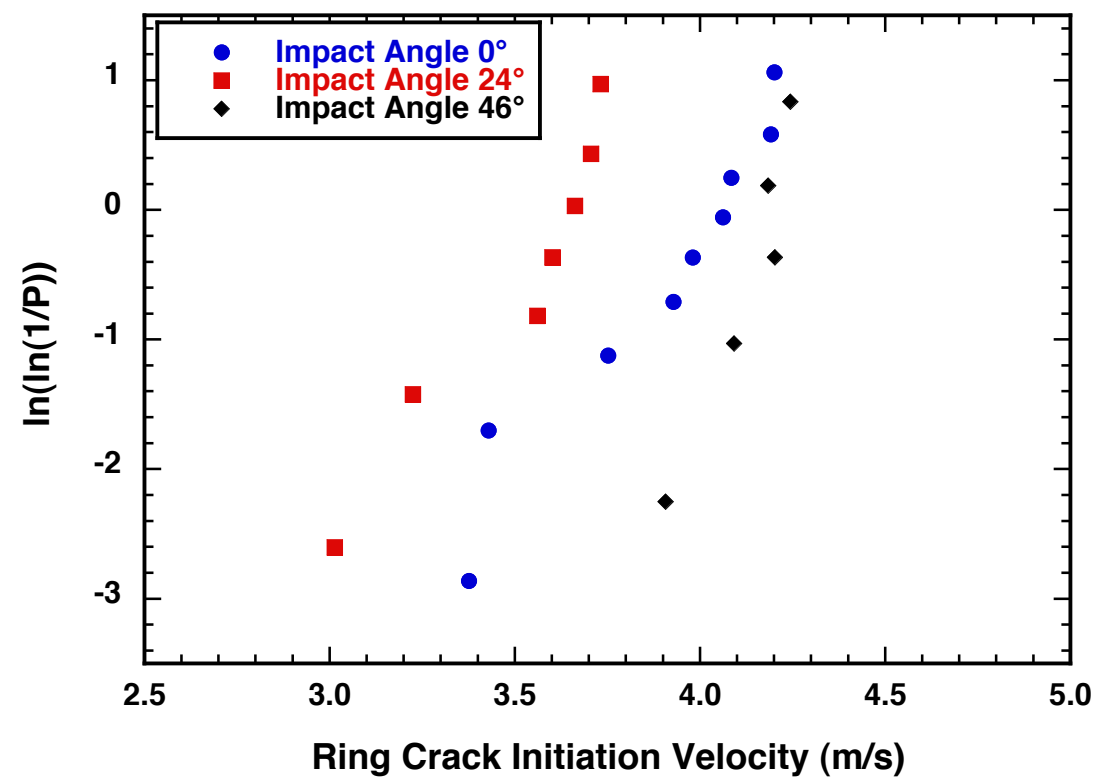

Figure 16. Weibull distribution of angled impact response.

\subsection{Location Dependent Indentation Response}

The summary of the location dependency of the RCIF across a BS tile is displayed with color mapping. A linear color-coding is applied with red representing the lowest RCIF and violet representing the highest RCIF, seen in Fig. 17. A blank square represents a misread RCIF and no data is collected at that location. 


\begin{tabular}{|c|c|c|c|c|c|c|c|c|c|}
\hline 495 & 1718 & 390 & 641 & 2634 & 817 & 665 & 1059 & 1993 & 434 \\
\hline 860 & 1041 & 502 & 462 & 629 & 532 & 520 & 301 & 883 & 466 \\
\hline 730 & 1223 & 849 & 857 & 388 & 643 & 418 & 576 & 733 & 505 \\
\hline 340 & 1254 & 1279 & 1047 & 542 & 1420 & 1048 & 1291 & 579 & 690 \\
\hline 1097 & 944 & 981 & 1113 & 556 & 983 & 1483 & & 606 & 469 \\
\hline 1622 & 1425 & 1342 & 777 & 631 & 1036 & 1982 & 813 & 606 & 731 \\
\hline 906 & 536 & 2411 & 1460 & 670 & 1321 & 327 & 395 & 439 & 607 \\
\hline 555 & 922 & 528 & 748 & 320 & 1083 & 435 & 732 & 271 & 476 \\
\hline 956 & 621 & 826 & 1337 & 519 & 925 & 1168 & 721 & 515 & 598 \\
\hline 803 & 1479 & 854 & 1055 & 380 & 912 & 1228 & 805 & 640 & \\
\hline
\end{tabular}

Figure 17 - RCIF of silicon nitride indenter on BS glass at approximate locations. Red is lowest value, violet is highest value.

There is a subtle indication there was intra-tile differences in spherical indentation RCIF. This likely is not a material property nor exclusive to borosilicate glass, rather, it is a statistical response of a combination of local, surface-located flaw and imposed tensile stress. 


\section{SUMMARY}

- Borosilicate glass responded similarly to soda-lime silicate glass to spherical indentation; however, under spherical impact it responded quite differently.

- Frictional effects contribute to fracture initiation in borosilicate (BS) glass when it is quasi-statically, spherically indented. This effect was also observed with soda-lime silicate glass.

- The force necessary to intiate fracture in borosilicate glass under spherical impact conditions decreases with increasing elastic modulus of the sphere material. This trend is opposite to what was observed with soda-lime silicate glass. Friction cannot explain this trend and a legitimate explanation of it presently eludes the authors.

- The force necessary to initiate contact-induced fracture is higher under dynamic conditions than it is under quasi-static conditions. That difference diminishes with increasing elastic modulus mismatch between the sphere material and borosilicate. This trend was opposite in soda-lime silicate glass.

- Fracture in borosilicate glass occurs at lower velocities at $24^{\circ}$ than at $0^{\circ}$ (orthogonal) and $46^{\circ}$ of impact for the same probability of failure. Impact at $46^{\circ}$ required the highest velocity among the three angles to initiate ring cracking.

- There is a subtle indication there was intra-tile differences in spherical indentation RCIF. This likely is not a material property nor exclusive to borosilicate glass, rather, it is a statistical response of a combination of local, surface-located flaw and imposed tensile stress.

- Contact-induced fracture did not initiate in the Borofloat BS for impact kinetic energies up to $\sim 20 \mathrm{~mJ}$. For kinetic energies between $\sim 20-150 \mathrm{~mJ}$, fracture sometimes initiated. Contact-induced fracture would always occur for impact energies $>150 \mathrm{~mJ}$. The energy values, and their boundaries, were much lower for BS glass than they were for soda-lime silicate glass. 


\section{REFERENCES}

[1] A. A. Wereszczak, E. E. Fox, T. G. Morrissey, and D. J. Vuono, "Low Velocity Sphere Impact of a Soda Lime Silicate Glass," ORNL/TM-2011/259, October, 2011.

[2] A. A. Wereszczak, W. L. Daloz, K. T. Strong, Jr., and O. M. Jadaan, "Effect of Indenter Elastic Modulus on Hertzian Ring Crack Initiation in Silicon Carbide," Int. J. Appl. Cer. Tech., 8:885-94 (2011).

[3] A. D. Peralta and H. Yoshida, "Design of Impact-Resistant Ceramic Structural Components," Chapter 28 in Ceramic Gas Turbine Component Development and Characterization, Volume 2, Eds. M. van Roode, M. K. Ferber, and D. W. Richerson, ASME Press, New York, 2003.

[4] C. G. Knight, M. V. Swain, and M. M. Chaudhri, "Impact of Small Steel Spheres on Glass Surfaces", J. Mat. Sci., 12:1573-86 (1977).

[5] S. Timoshenko and J. N. Goodier, Theory of Elasticity, McGraw-Hill Book Co., New York, 1951.

[6] K. L. Johnson, J. J O'Connor, and A. C. Woodward, "The Effect of the Indenter Elasticity on the Hertzian Fracture of Brittle Materials," Proc. R. Soc. London, 334:95117 (1973).

[7] J. Dundurs, "Edge-Bounded Dissimilar Orthogonal Elastic Wedges Under Normal and Shear Loading," J. Appl. Mech., 36:650-652 (1969).

[8] A. A. Wereszczak, T. P. Kirkland, K. T. Strong, Jr., and T. J. Holmquist, "ORNL QuasiStatic Mechanical Characterization and Analysis: FY09 Annual Report to TARDEC," ORNL/TM-2009/234 Report, December, 2009.

[9] A. A. Wereszczak, "Elastic Property Determination of WC Spheres and Estimation of Compressive Loads and Impact Velocities That Initiate Their Yielding and Cracking," Cer. Eng. Sci. Proc., [7] 27:211-223 (2006).

[10] J. P. A. Tillett, "Fracture of Glass by Spherical Indenters," Proc. Phys. Soc. B., 69:47-54 (1956). 


\section{ACKNOWLEDGMENTS}

Research performed under Work For Others funded by U.S. Army Tank-Automotive Research, Development and Engineering Center, under contract DE-AC-00OR22725 with UT-Battelle, LLC.

The authors wish to express sincere appreciation to A. Dolan of the U.S. Army Research, Development and Engineering Command - Tank-Automotive and Armaments Command for sponsoring this work, US Army Research Laboratory's P. Patel for supplying the borosilicate tiles, and ORNL's C. Ayers and R. Wiles for their review of this report and helpful comments.

This submission was produced by a contractor of the United States Government under contract DE-AC05-00OR22725 with the United States Department of Energy. The United States Government retains, and the publisher, by accepting this submission for publication, acknowledges that the United States Government retains, a nonexclusive, paid-up, irrevocable, worldwide license to publish or reproduce the published form of this submission, or allow others to do so, for United States Government purposes.

The US Army TARDEC OPSEC Review Certification number for this manuscript is 22749. As the authors are not Government employees, this document was only OPSEC reviewed for export controls, and improper Army association or emblem usage considerations. All other legal considerations are the responsibility of the authors and UT-Battelle, LLC. 


\section{APPENDIX I}

\begin{tabular}{|c|c|c|c|c|c|c|}
\hline $\begin{array}{c}\text { Sphere } \\
\text { Material }\end{array}$ & $\begin{array}{c}\text { Gas Gun } \\
\text { Pressure } \\
\text { (psi) }\end{array}$ & $\begin{array}{c}\text { Ball Drop } \\
\text { Height } \\
\text { (m) }\end{array}$ & $\begin{array}{c}\text { Impact } \\
\text { Velocity } \\
(\mathbf{m} / \mathbf{s})\end{array}$ & $\begin{array}{c}\text { Kinetic } \\
\text { Energy } \\
(\mathrm{mJ})\end{array}$ & $\begin{array}{c}\text { Visible } \\
\text { Damage }\end{array}$ & $\begin{array}{c}P \max \\
(\mathrm{N})\end{array}$ \\
\hline BS Glass & & 0.381 & 2.69 & 9 & $\mathrm{n}$ & 655 \\
\hline BS Glass & & 0.457 & 2.83 & 10 & $\mathrm{n}$ & 696 \\
\hline BS Glass & & 0.533 & 3.15 & 12 & $\mathrm{n}$ & 791 \\
\hline BS Glass & & 0.610 & 3.37 & 14 & $\mathrm{n}$ & 858 \\
\hline BS Glass & & 0.686 & 3.56 & 15 & $\mathrm{n}$ & 916 \\
\hline BS Glass & & 0.762 & 3.73 & 17 & $\mathrm{n}$ & 969 \\
\hline BS Glass & & 0.838 & 3.91 & 18 & $\mathrm{n}$ & 1025 \\
\hline BS Glass & & 0.914 & 3.63 & 16 & $\mathrm{n}$ & 938 \\
\hline BS Glass & & 0.991 & 4.24 & 21 & $\mathrm{n}$ & 1130 \\
\hline BS Glass & & 1.143 & 4.49 & 24 & $\mathrm{n}$ & 1210 \\
\hline BS Glass & & 1.145 & 4.22 & 21 & $\mathrm{n}$ & 1124 \\
\hline BS Glass & & 1.753 & 5.18 & 32 & $\mathrm{n}$ & 1437 \\
\hline BS Glass & & 2.057 & 2.27 & 6 & $\mathrm{n}$ & 534 \\
\hline BS Glass & & 2.667 & 6.56 & 51 & $\mathrm{n}$ & 1908 \\
\hline BS Glass & 8.5 & & 11.37 & 154 & $\mathrm{y}$ & 3691 \\
\hline BS Glass & 10 & & 12.44 & 185 & $\mathrm{y}$ & 4112 \\
\hline SLS glass & & 1.753 & 5.34 & 38 & $\mathrm{n}$ & 1656 \\
\hline SLS glass & & 2.299 & 6.18 & 51 & $\mathrm{n}$ & 1974 \\
\hline SLS glass & & 2.299 & 6.19 & 52 & $\mathrm{n}$ & 1978 \\
\hline SLS glass & 6 & & 4.34 & 25 & $\mathrm{n}$ & 1292 \\
\hline SLS glass & 7.5 & & 10.30 & 143 & $\mathrm{n}$ & 3644 \\
\hline SLS glass & 7.5 & & 10.30 & 143 & $\mathrm{n}$ & 3644 \\
\hline SLS glass & 9.8 & & 12.70 & 217 & $\mathrm{y}$ & 4685 \\
\hline SLS glass & 10 & & 13.16 & 233 & $\mathrm{y}$ & 4889 \\
\hline Carbon Steel & & 0.305 & 2.36 & 23 & $\mathrm{n}$ & 1462 \\
\hline Carbon Steel & & 0.381 & 2.56 & 27 & $\mathrm{n}$ & 1612 \\
\hline Carbon Steel & & 0.457 & 2.91 & 35 & $\mathrm{n}$ & 1880 \\
\hline Carbon Steel & & 0.533 & 2.93 & 36 & $\mathrm{n}$ & 1895 \\
\hline Carbon Steel & & 0.610 & 3.39 & 48 & $\mathrm{n}$ & 2258 \\
\hline Carbon Steel & & 0.686 & 3.60 & 54 & $\mathrm{n}$ & 2426 \\
\hline Carbon Steel & & 0.762 & 3.68 & 57 & $\mathrm{y}$ & 2491 \\
\hline Carbon Steel & & 0.762 & 3.71 & 58 & $\mathrm{y}$ & 2516 \\
\hline Chrome Steel & & 0.686 & 3.59 & 54 & $\mathrm{n}$ & 2441 \\
\hline Chrome Steel & & 0.686 & 3.59 & 54 & $\mathrm{y}$ & 2441 \\
\hline Chrome Steel & & 0.686 & 3.59 & 54 & $\mathrm{y}$ & 2441 \\
\hline
\end{tabular}




\begin{tabular}{|c|c|c|c|c|c|}
\hline Chrome Steel & 0.762 & 3.52 & 52 & $\mathrm{y}$ & 2384 \\
\hline Chrome Steel & 0.762 & 3.60 & 54 & $\mathrm{y}$ & 2449 \\
\hline Zirconia & 0.686 & 3.51 & 40 & $\mathrm{n}$ & 1975 \\
\hline Zirconia & 0.762 & 3.81 & 47 & $\mathrm{n}$ & 2179 \\
\hline Zirconia & 0.838 & 3.77 & 46 & $\mathrm{n}$ & 2152 \\
\hline Zirconia & 0.838 & 3.77 & 46 & $\mathrm{n}$ & 2152 \\
\hline Zirconia & 0.914 & 3.59 & 42 & $\mathrm{n}$ & 2029 \\
\hline Zirconia & 0.914 & 3.87 & 49 & $\mathrm{y}$ & 2221 \\
\hline Zirconia & 0.914 & 4.14 & 56 & $\mathrm{y}$ & 2408 \\
\hline $\mathrm{Si}_{3} \mathrm{~N}_{4}$ & 0.762 & 3.08 & 16 & $\mathrm{n}$ & 1132 \\
\hline $\mathrm{Si}_{3} \mathrm{~N}_{4}$ & 0.686 & 3.38 & 19 & $\mathrm{n}$ & 1265 \\
\hline $\mathrm{Si}_{3} \mathrm{~N}_{4}$ & 0.686 & 3.56 & 22 & $\mathrm{n}$ & 1349 \\
\hline $\mathrm{Si}_{3} \mathrm{~N}_{4}$ & 0.699 & 3.36 & 19 & $\mathrm{n}$ & 1258 \\
\hline $\mathrm{Si}_{3} \mathrm{~N}_{4}$ & 0.762 & 3.52 & 21 & $\mathrm{n}$ & 1327 \\
\hline $\mathrm{Si}_{3} \mathrm{~N}_{4}$ & 0.762 & 3.38 & 19 & $\mathrm{y}$ & 1264 \\
\hline $\mathrm{Si}_{3} \mathrm{~N}_{4}$ & 0.762 & 3.43 & 20 & $\mathrm{y}$ & 1288 \\
\hline $\mathrm{Si}_{3} \mathrm{~N}_{4}$ & 0.775 & 3.95 & 26 & $\mathrm{n}$ & 1525 \\
\hline $\mathrm{Si}_{3} \mathrm{~N}_{4}$ & 0.838 & 3.93 & 26 & $\mathrm{n}$ & 1516 \\
\hline $\mathrm{Si}_{3} \mathrm{~N}_{4}$ & 0.838 & 3.98 & 27 & $\mathrm{y}$ & 1540 \\
\hline $\mathrm{Si}_{3} \mathrm{~N}_{4}$ & 0.851 & 4.06 & 28 & $\mathrm{n}$ & 1578 \\
\hline $\mathrm{Si}_{3} \mathrm{~N}_{4}$ & 0.851 & 4.06 & 28 & $\mathrm{n}$ & 1579 \\
\hline $\mathrm{Si}_{3} \mathrm{~N}_{4}$ & 0.851 & 4.07 & 28 & $\mathrm{n}$ & 1580 \\
\hline $\mathrm{Si}_{3} \mathrm{~N}_{4}$ & 0.851 & 4.06 & 28 & $\mathrm{y}$ & 1579 \\
\hline $\mathrm{Si}_{3} \mathrm{~N}_{4}$ & 0.851 & 3.75 & 24 & $\mathrm{y}$ & 1435 \\
\hline $\mathrm{Si}_{3} \mathrm{~N}_{4}$ & 0.851 & 4.08 & 28 & $\mathrm{y}$ & 1589 \\
\hline $\mathrm{Si}_{3} \mathrm{~N}_{4}$ & 0.927 & 4.20 & 30 & $\mathrm{y}$ & 1643 \\
\hline $\mathrm{Si}_{3} \mathrm{~N}_{4}$ & 0.927 & 4.19 & 30 & $\mathrm{y}$ & 1639 \\
\hline $\mathrm{Al}_{2} \mathrm{O}_{3}$ & 0.686 & 3.39 & 24 & $\mathrm{n}$ & 1446 \\
\hline $\mathrm{Al}_{2} \mathrm{O}_{3}$ & 0.762 & 3.78 & 30 & $\mathrm{n}$ & 1648 \\
\hline $\mathrm{Al}_{2} \mathrm{O}_{3}$ & 0.838 & 3.69 & 29 & $\mathrm{n}$ & 1601 \\
\hline $\mathrm{Al}_{2} \mathrm{O}_{3}$ & 0.762 & 3.77 & 30 & $\mathrm{n}$ & 1643 \\
\hline $\mathrm{Al}_{2} \mathrm{O}_{3}$ & 0.838 & 3.73 & 29 & $\mathrm{y}$ & 1622 \\
\hline $\mathrm{Al}_{2} \mathrm{O}_{3}$ & 0.914 & 4.40 & 41 & $\mathrm{y}$ & 1977 \\
\hline $\mathrm{Al}_{2} \mathrm{O}_{3}$ & 0.914 & 4.12 & 36 & $\mathrm{y}$ & 1827 \\
\hline
\end{tabular}




\section{APPENDIX II}

\begin{tabular}{|c|c|c|c|c|c|c|}
$\begin{array}{c}\text { Sphere } \\
\text { Material }\end{array}$ & Angle & $\begin{array}{c}\text { Ball Drop } \\
\text { Height }\end{array}$ & $\begin{array}{c}\text { Impact } \\
\text { Velocity } \\
\text { (m/s) }\end{array}$ & $\begin{array}{c}\text { Kinetic } \\
\text { Energy } \\
(\mathbf{m J})\end{array}$ & $\begin{array}{c}\text { Visible } \\
\text { Damage }\end{array}$ & $\begin{array}{c}\text { P max } \\
\text { (N) }\end{array}$ \\
\hline $\mathrm{Si}_{3} \mathrm{~N}_{4}$ & 0 & 0.762 & 3.08 & 16 & $\mathrm{n}$ & 1132 \\
\hline $\mathrm{Si}_{3} \mathrm{~N}_{4}$ & 0 & 0.686 & 3.38 & 19 & $\mathrm{n}$ & 1265 \\
\hline $\mathrm{Si}_{3} \mathrm{~N}_{4}$ & 0 & 0.686 & 3.56 & 22 & $\mathrm{n}$ & 1349 \\
\hline $\mathrm{Si}_{3} \mathrm{~N}_{4}$ & 0 & 0.699 & 3.36 & 19 & $\mathrm{n}$ & 1258 \\
\hline $\mathrm{Si}_{3} \mathrm{~N}_{4}$ & 0 & 0.762 & 3.52 & 21 & $\mathrm{n}$ & 1327 \\
\hline $\mathrm{Si}_{3} \mathrm{~N}_{4}$ & 0 & 0.762 & 3.38 & 19 & $\mathrm{y}$ & 1264 \\
\hline $\mathrm{Si}_{3} \mathrm{~N}_{4}$ & 0 & 0.762 & 3.43 & 20 & $\mathrm{y}$ & 1288 \\
\hline $\mathrm{Si}_{3} \mathrm{~N}_{4}$ & 0 & 0.775 & 3.95 & 26 & $\mathrm{n}$ & 1525 \\
\hline $\mathrm{Si}_{3} \mathrm{~N}_{4}$ & 0 & 0.838 & 3.93 & 26 & $\mathrm{n}$ & 1516 \\
\hline $\mathrm{Si}_{3} \mathrm{~N}_{4}$ & 0 & 0.838 & 3.98 & 27 & $\mathrm{y}$ & 1540 \\
\hline $\mathrm{Si}_{3} \mathrm{~N}_{4}$ & 0 & 0.851 & 4.06 & 28 & $\mathrm{n}$ & 1578 \\
\hline $\mathrm{Si}_{3} \mathrm{~N}_{4}$ & 0 & 0.851 & 4.06 & 28 & $\mathrm{n}$ & 1579 \\
\hline $\mathrm{Si}_{3} \mathrm{~N}_{4}$ & 0 & 0.851 & 4.07 & 28 & $\mathrm{n}$ & 1580 \\
\hline $\mathrm{Si}_{3} \mathrm{~N}_{4}$ & 0 & 0.851 & 4.06 & 28 & $\mathrm{y}$ & 1579 \\
\hline $\mathrm{Si}_{3} \mathrm{~N}_{4}$ & 0 & 0.851 & 3.75 & 24 & $\mathrm{y}$ & 1435 \\
\hline $\mathrm{Si}_{3} \mathrm{~N}_{4}$ & 0 & 0.851 & 4.08 & 28 & $\mathrm{y}$ & 1589 \\
\hline $\mathrm{Si}_{3} \mathrm{~N}_{4}$ & 0 & 0.927 & 4.20 & 30 & $\mathrm{y}$ & 1643 \\
\hline $\mathrm{Si}_{3} \mathrm{~N}_{4}$ & 0 & 0.927 & 4.19 & 30 & $\mathrm{y}$ & 1639 \\
\hline & & & & & & \\
\hline
\end{tabular}

\begin{tabular}{|c|c|c|c|c|c|c|}
\hline $\mathrm{Si}_{3} \mathrm{~N}_{4}$ & 24 & 0.610 & 3.23 & 18 & $\mathrm{y}$ & 1197 \\
\hline $\mathrm{Si}_{3} \mathrm{~N}_{4}$ & 24 & 0.610 & 2.33 & 9 & $\mathrm{n}$ & 809 \\
\hline $\mathrm{Si}_{3} \mathrm{~N}_{4}$ & 24 & 0.610 & 3.40 & 20 & $\mathrm{n}$ & 1274 \\
\hline $\mathrm{Si}_{3} \mathrm{~N}_{4}$ & 24 & 0.610 & 2.28 & 9 & $\mathrm{n}$ & 791 \\
\hline $\mathrm{Si}_{3} \mathrm{~N}_{4}$ & 24 & 0.610 & 3.01 & 15 & $\mathrm{y}$ & 1103 \\
\hline $\mathrm{Si}_{3} \mathrm{~N}_{4}$ & 24 & 0.610 & 3.16 & 17 & $\mathrm{n}$ & 1167 \\
\hline $\mathrm{Si}_{3} \mathrm{~N}_{4}$ & 24 & 0.610 & 3.42 & 20 & $\mathrm{n}$ & 1283 \\
\hline $\mathrm{Si}_{3} \mathrm{~N}_{4}$ & 24 & 0.610 & 3.16 & 17 & $\mathrm{n}$ & 1169 \\
\hline $\mathrm{Si}_{3} \mathrm{~N}_{4}$ & 24 & 0.660 & 3.52 & 21 & $\mathrm{n}$ & 1327 \\
\hline $\mathrm{Si}_{3} \mathrm{~N}_{4}$ & 24 & 0.660 & 3.31 & 19 & $\mathrm{n}$ & 1234 \\
\hline $\mathrm{Si}_{3} \mathrm{~N}_{4}$ & 24 & 0.686 & 3.60 & 22 & $\mathrm{y}$ & 1367 \\
\hline $\mathrm{Si}_{3} \mathrm{~N}_{4}$ & 24 & 0.686 & 3.56 & 21 & $\mathrm{y}$ & 1348 \\
\hline $\mathrm{Si}_{3} \mathrm{~N}_{4}$ & 24 & 0.686 & 3.62 & 22 & $\mathrm{n}$ & 1376 \\
\hline $\mathrm{Si}_{3} \mathrm{~N}_{4}$ & 24 & 0.686 & 3.61 & 22 & $\mathrm{n}$ & 1371 \\
\hline $\mathrm{Si}_{3} \mathrm{~N}_{4}$ & 24 & 0.737 & 3.73 & 24 & $\mathrm{y}$ & 1426 \\
\hline $\mathrm{Si}_{3} \mathrm{~N}_{4}$ & 24 & 0.737 & 3.71 & 23 & $\mathrm{n}$ & 1414 \\
\hline $\mathrm{Si}_{3} \mathrm{~N}_{4}$ & 24 & 0.737 & 3.71 & 23 & $\mathrm{n}$ & 1414 \\
\hline $\mathrm{Si}_{3} \mathrm{~N}_{4}$ & 24 & 0.737 & 3.71 & 23 & $\mathrm{y}$ & 1414 \\
\hline
\end{tabular}




\begin{tabular}{|l|l|l|l|l|l|l|}
$\mathrm{Si}_{3} \mathrm{~N}_{4}$ & 24 & 0.762 & 3.61 & 22 & $\mathrm{n}$ & 1372 \\
\hline $\mathrm{Si}_{3} \mathrm{~N}_{4}$ & 24 & 0.762 & 3.80 & 24 & $\mathrm{n}$ & 1457 \\
\hline $\mathrm{Si}_{3} \mathrm{~N}_{4}$ & 24 & 0.762 & 3.66 & 23 & $\mathrm{y}$ & 1394 \\
\hline
\end{tabular}

\begin{tabular}{|l|l|l|l|l|l|l|}
\hline $\mathrm{Si}_{3} \mathrm{~N}_{4}$ & 46 & 0.635 & 3.38 & 19 & $\mathrm{n}$ & 1266 \\
\hline $\mathrm{Si}_{3} \mathrm{~N}_{4}$ & 46 & 0.711 & 3.66 & 23 & $\mathrm{n}$ & 1394 \\
\hline $\mathrm{Si}_{3} \mathrm{~N}_{4}$ & 46 & 0.787 & 3.75 & 24 & $\mathrm{n}$ & 1433 \\
\hline $\mathrm{Si}_{3} \mathrm{~N}_{4}$ & 46 & 0.864 & 3.91 & 26 & $\mathrm{y}$ & 1507 \\
\hline $\mathrm{Si}_{3} \mathrm{~N}_{4}$ & 46 & 0.864 & 4.04 & 28 & $\mathrm{n}$ & 1569 \\
\hline $\mathrm{Si}_{3} \mathrm{~N}_{4}$ & 46 & 0.864 & 4.01 & 27 & $\mathrm{n}$ & 1552 \\
\hline $\mathrm{Si}_{3} \mathrm{~N}_{4}$ & 46 & 0.940 & 4.09 & 28 & $\mathrm{y}$ & 1593 \\
\hline $\mathrm{Si}_{3} \mathrm{~N}_{4}$ & 46 & 0.940 & 4.12 & 29 & $\mathrm{n}$ & 1608 \\
\hline $\mathrm{Si}_{3} \mathrm{~N}_{4}$ & 46 & 0.940 & 4.12 & 29 & $\mathrm{n}$ & 1608 \\
\hline $\mathrm{Si}_{3} \mathrm{~N}_{4}$ & 46 & 0.940 & 4.20 & 30 & $\mathrm{y}$ & 1644 \\
\hline $\mathrm{Si}_{3} \mathrm{~N}_{4}$ & 46 & 0.940 & 4.18 & 30 & $\mathrm{n}$ & 1636 \\
\hline $\mathrm{Si}_{3} \mathrm{~N}_{4}$ & 46 & 0.940 & 4.18 & 30 & $\mathrm{y}$ & 1636 \\
\hline $\mathrm{Si}_{3} \mathrm{~N}_{4}$ & 46 & 0.940 & 4.19 & 30 & $\mathrm{n}$ & 1639 \\
\hline $\mathrm{Si}_{3} \mathrm{~N}_{4}$ & 46 & 0.940 & 3.88 & 25 & $\mathrm{n}$ & 1493 \\
\hline $\mathrm{Si}_{3} \mathrm{~N}_{4}$ & 46 & 0.940 & 3.77 & 24 & $\mathrm{n}$ & 1442 \\
\hline $\mathrm{Si}_{3} \mathrm{~N}_{4}$ & 46 & 1.016 & 4.16 & 29 & $\mathrm{n}$ & 1626 \\
\hline $\mathrm{Si}_{3} \mathrm{~N}_{4}$ & 46 & 1.016 & 4.29 & 31 & $\mathrm{n}$ & 1685 \\
\hline $\mathrm{Si}_{3} \mathrm{~N}_{4}$ & 46 & 1.016 & 4.24 & 31 & $\mathrm{y}$ & 1664 \\
\hline
\end{tabular}

